\title{
Working
}

Paper 


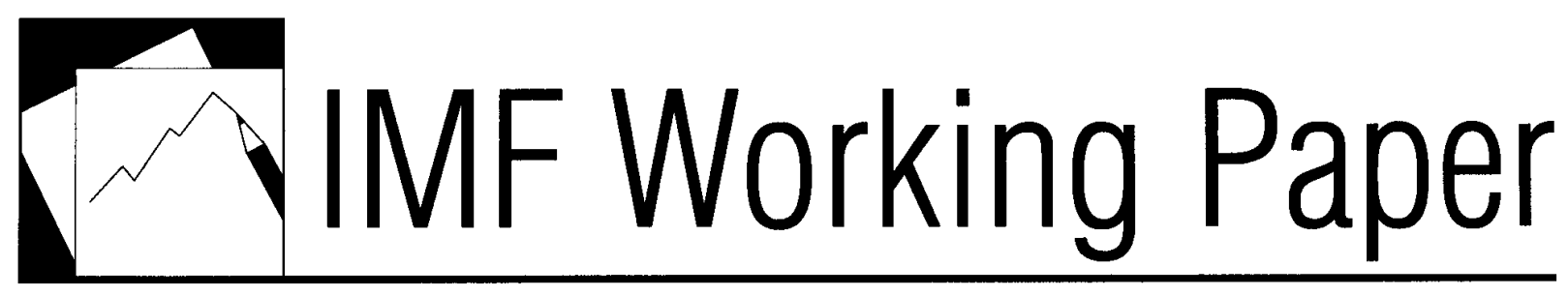

\section{Education Attainment in Public Administration Around the World: Evidence from a New Dataset}

Rabah Arezki, Herbert Lui, Marc Quintyn, and Frederik Toscani 


\title{
IMF Working Paper
}

Institute for Capacity Development

\section{Education Attainment in Public Administrations around the World: Evidence from a New Dataset}

\author{
Prepared by Rabah Arezki, Herbert Lui, Marc Quintyn, and Frederik Toscani ${ }^{1}$
}

Authorized for distribution by Marc Quintyn

September 2012

\section{This Working Paper should not be reported as representing the views of the IMF.}

The views expressed in this Working Paper are those of the author(s) and do not necessarily represent those of the IMF or IMF policy. Working Papers describe research in progress by the author(s) and are published to elicit comments and to further debate.

\begin{abstract}
The paper provides a detailed description of a novel dataset on education attainment in public administrations covering the period 1981-2011 for 178 countries. The dataset uses information extracted from CVs for over 130,000 mid to senior level officials from mainly central banks and ministries of economy and finance. Our main finding is that there is little heterogeneity across regions when considering a non quality-adjusted measure of education attainment in public administrations. Adjusting our measure for quality, using a country wide academic ranking, reveals important cross-regional heterogeneity differing from that of standard measures of education attainment for the general population. The dataset also allows us to uncover important patterns in public administrations' education attainment along gender and seniority across regions. We further use the dataset to explore a few applications which provide some evidence of (i) the importance of salary incentives in attracting highly educated staff and (ii) a positive association between education attainment in public administrations and government effectiveness (e.g. higher tax revenue mobilization, limiting corruption, better public finance management and private market support).
\end{abstract}

JEL Classification Numbers: E60, F34, H21

Keywords: Education Attainment, Public Administration, State Capacity.

Author’s E-Mail Address: rarezki@imf.org; hlui@imf.org; mquintyn@imf.org; ftoscani@imf.org

\footnotetext{
${ }^{1}$ The authors gratefully acknowledge IMF Institute for Capacity Development seminar participants, George Akerlof, Dominique Desruelle, Alan Gelb, Kirk Hamilton, Prakash Loungani, Constant Lonkeng, Alan MacArthur, Caryl McNeilly, Martin Rama, and Catherine Pattillo for helpful comments and suggestions. We also thank Benedict Clements and Michael Keen for sharing their datasets. All remaining errors are ours. The views expressed in this paper are those of the authors and do not necessarily reflect those of the International Monetary Fund, its Board of Directors or the countries they represent.
} 


\section{Contents}

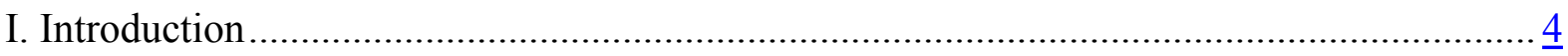

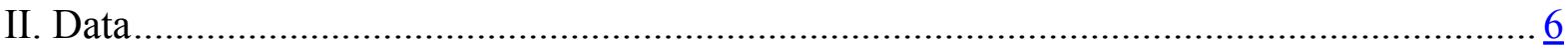

A. Applicants' CVs ................................................................................... $\frac{6}{6}$

B. Issues of sample representativity ..............................................................

III. Our measure(s) of education attainment in public administrations................................ $\underline{8}$

A. Non quality adjusted measure of education attainment................................... $\underline{8}$

B. Quality adjusted education attainment in public administrations........................ $\underline{8}$

C. Seniority and Gender .......................................................................... 10

Seniority ….........................................................................

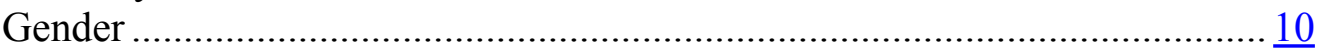

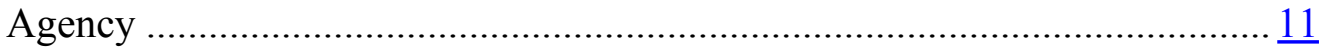

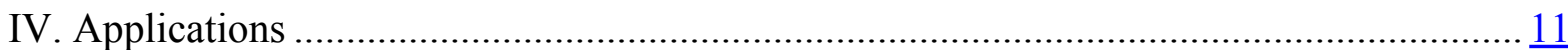

A. About Incentives................................................................................. 11

B. About government effectiveness ……....................................................

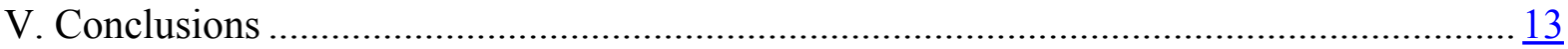

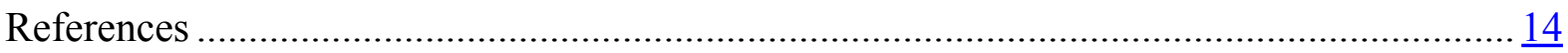

Tables

Table 1. Country Level Academic Ranking................................................................ 40

\section{Figures}

Figure 1. Education Attainment in the General Population around the World ..................... 17

Figure 2. Example of Official's CV ............................................................................ 17

Figure 3. Overview of the Distribution of Age in Sample ............................................ 18

Figure 4. Age Distribution by Region .................................................................... 18

Figure 5. Gender Distribution by Region...................................................................... 19

Figure 6. Age Distribution by Type of Course............................................................ 20

Figure 7. Fraction of Officials with Tertiary Education by Region .................................. 21

Figure 8. Education Attainments: Public Administration vs. General Population................. 21

Figure 9. Average Years of Tertiary Education in Public Administrations .......................... 22

Figure 10. Fraction of officials with a degree from a country ranked in the top $48 \ldots \ldots \ldots \ldots . \underline{23}$

Figure 11. Normalized weighted years of tertiary education by region............................. 24

Figure 12. Adjusted vs. non adjusted education attainment in public administration ........... $\frac{25}{26}$

Figure 13. Ratio of public administrations' education attainment in public ........................ $\underline{26}$

Figure 14. Education attainment by rank and region .............................................. 27

Figure 15. Education attainment by seniority and region ............................................ 28

Figure 16. Gender differences in education attainment in public administrations................ $\underline{29}$

Figure 17. Fraction of Managers who are male ....................................................... $\underline{30}$

Figure 18. Fraction of senior managers who are male ................................................. $\frac{31}{32}$

Figure 19. Education Attainment by Agency and Region .......................................... $\underline{32}$ 
Figure 20. Education attainment and Relative Public Sector Pay .......................................... $\frac{33}{34}$

Figure 21. Education attainment and tax collectio .......................................................... $\frac{34}{34}$

Figure 22. Education attainment and tax revenues controlling GDP per education and.......... $\frac{34}{35}$

Figure 23. Education attainment and corruption ............................................................. $\frac{35}{36}$

Figure 24. Education Attainment and Corruption controlling for GDP per capita and ........... $\underline{36}$

Figure 25. Education Attainment and Public Sector Management ......................................... $\frac{37}{38}$

Figure 26. Education attainment and bureaucratic quality ............................................... $\frac{38}{38}$

Figure 27. Education and Domestic Financial Sector Standards ............................................ 39

\section{Appendixes}

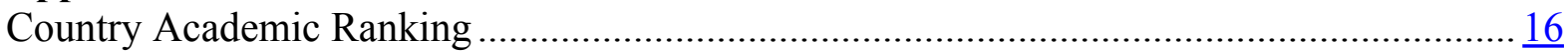




\section{INTRODUCTION}

There are several reasons for why governments might fail. Besley (2002) argues that "government might fail because of ignorance, influence (corruption and rent seeking), and the quality of leaders". Along the same line, Chong, La Porta, Lopez-de-Silanes, and Shleifer, (2012) argue that "there are two reasons for bad government in developing countries: political economy and productivity. The political economy arguments hold that governments in poor countries are less accountable because citizens have few opportunities to exercise their voice [..... An alternative view of bad government in developing countries holds that low productivity of government services is explained by the same factors as that in the private sector. Part of the problem might be inferior inputs, including human and physical capital as well as technology. Part of the problem might also be poor management, including the lack of supervision and monitoring".

These quotes suggest that, from a conceptual standpoint, the set of driving forces behind government (in)effectiveness are known. What is less known is the empirical relevance of each of those driving forces. To be able to make progress on that front, we first need to document systematically the characteristics of the inputs that go into public administration. In the present paper, we shed light specifically on the human capital which acts as an input into public administrations around the world.

While data on education attainment is available for the general population, it is simply not available for public administrations. According to Barro and Lee (2010), there are large differences in education attainment of the general population across countries. As shown in Figure 1, they find that in 2010 the gap between rich (11.0) and poor countries (7.1) in average years of schooling was 4 years. Those measures have been widely used throughout the economic literature. Differences in education attainment in the general population may not translate to similar differences in civil servants' education attainment in public administrations. In fact, we know so little about the characteristics of public administrations than not even the information on the numbers of civil servants is consistently available across countries, let alone over time. This paper attempts to fill the gap by building a novel dataset on education attainment in public administrations. Using this dataset, we show that levels of education attainment in public administration across regions are quite different from those of the general population.

This paper provides a detailed description of a novel dataset on education attainment in public administrations covering the period 1981-2011 for 178 countries. The dataset uses information extracted from CVs for over 130,000 mid to senior level officials from mainly central banks and ministries of economy and finance. Our main finding is that there is little heterogeneity across regions when considering a non quality-adjusted measure of education attainment in public administrations. Adjusting our measure for quality using a country-wide academic ranking reveals important cross-regional heterogeneity differing from that of standard measures of education attainment for the general population. The dataset also allows us to uncover important patterns in public administrations' education attainment along gender and seniority across regions. We further use the dataset to explore a few applications which provide some evidence of (i) the importance of salary incentives in attracting highly educated staff and (ii) a positive association between education attainment in public administrations and 
government effectiveness (e.g. higher tax revenue mobilization, limiting corruption, better public finance management and private market support).

Our paper relates to several strands of the economics literature. Most immediately, our paper relates to the literature on education attainment in the general population (Barro and Lee, 2010). They construct measures of educational attainment of the adult population for 146 countries at 5-year intervals from 1950 to 2010 disaggregated by gender and by 5-year age groups. Their measure (and related ones such as the one developed by Cohen and Soto (2007)) have been used widely in the literature on economic growth, income inequality, technological adoption, fertility and democratization. Our paper contributes to this strand of the literature by providing insights into education attainment in public administration which may shed further light into the empirical explanation as to why and when governments are ineffective.

Our paper also relates to the literature on state capacity and state building. Besley and Perrson (2006) find that legal and fiscal capacities are complements in determining investment in state capacity. They also find that common interest public goods, political stability and inclusive political institutions are conducive to state capacity. Andrew, Pritchett and Woolcok (2012) argue that governments often pretend to reform by changing what policies look like, rather than what they actually do. They further argue that this "development rhetoric" often leads to "capability traps" because it lacks focus on performance improvement. Arezki, Dupuy and Gelb (2012) show theoretically that, following a windfall, governments should optimally decrease public investment when administrative capacity is weak. They show that instead governments should engage in direct redistribution provided that the latter could be achieved avoiding capture. Botero, Ponce and Shleifer (2012) show that when the education level of the general population is high, citizens are more likely to effectively hold governments to account and thus instigate government discipline. Chong, La Porta, Lopez-de-Silanes, and Shleifer (2012) introduce a measure of government efficiency based on the ability to return an incorrectly addressed international letter (à la Putnam, 1993). In a way their paper could be viewed as a close complement to ours since it evaluates government effectiveness in dealing with a very simple task which should not require any advanced education whereas we are interested in the level of human capital which acts as an input at the level of government policy making and implementation. More generally, our paper contributes to the literature on state capacity by empirically documenting the differences in human capital endowment between countries which in turn will help us get a better grasp over the different explanations as to why governments fail.

Lastly, our paper also relates to the literature on leaders and the impact of the latter on economic performance. Jones and Olken (2005), using a unique instrument for change in leadership based on deaths of leaders while in office, provide empirical evidence that leaders do cause economic growth. Besley et al. (2011) further provide empirical evidence that the educational attainment of leaders matters for economic growth. These papers document that education attainment at the very top of the pyramid of government is an important factor. Our paper contributes to this strand of the literature by expanding the view to the education attainment of those officials who influence policy implementation on a day to day basis. 
To the extent of our knowledge, we are the first to document systematically the characteristics of education attainment in public administration. While our data may not cover the whole spectrum of public servants (we focus on mid to high level officials in central governments) and may be limited in scope (we focus on central banks and ministries of finance and economics), we believe we do make an important contribution by shedding light in an area where so little systematic documentation is available. Also, while we believe documenting the characteristics of officials at a lower level of hierarchy and outside central government is important, we believe that mid to higher level officials play a key role in policy making. We see this work as a first attempt to document systematically characteristics of public administrations around the world.

The remainder of the paper is organized as follows. Section II provides a discussion of the methodology used to compile the data and issues related to data consistency. Section III discusses the patterns emerging from cross-regional comparison of our various measures of education attainments. Section IV presents a few exploratory applications using our novel dataset. Section V concludes.

\section{DATA}

In this section, we discuss the source and nature of the underlying information on civil servants used to compile our dataset on educational attainment in public administrations. We further discuss issues of representativity of our sample.

\section{A. Applicants' CVs}

The dataset is a compilation of tabulated information from 131,877 CVs of civil servants who have applied to International Monetary Fund (IMF) training activities during the period 19812011 from 178 countries. The IMF Institute for Capacity Development's Participant and Applicant Tracking System (PATS), the repository for the CVs, includes country of residence, agency, age, gender, position and detailed educational background (e.g. degree, graduating institution, study abroad...). Figure 2 describes the standard format of the CVs available in PATS. The IMF capacity building activities include a broad variety of courses that include all aspects of macroeconomic policy, national statistics and more specialized courses, such as finance. Those courses are offered either in a regional location or at IMF headquarters in Washington, DC. Courses could be either by nomination by country authorities or by spontaneous application. Those courses are often oversubscribed and, thus, provide us with a large pool of applicants. As an example, the 2012 offering of the IMF headquarters' course on macroeconomic management and fiscal policy in French has received over 400 applications. For expositional purposes, we describe the patterns emerging from the analysis of the data for the last ten years only thus using 41,019 unique applicants. It should however be noted that the data is available at five year intervals during 1981-2011.

\section{B. Issues of sample representativity}

We now turn to discuss the representativity of our sample. The sample size varies between countries, but on average the sample size is about 135 observations per country over the last ten years. A priori, this is a reasonably large number of observations. 
In the following, we focus on age and gender distribution to discuss issues of representativity as the former could be seen a synthesizing a variety of characteristics including seniority. A cursory look at the data suggests that the age distribution is skewed to the right. The median is around thirty years as shown in Figure 3. While the overall age distribution could appear relatively young, age groups ranging from 20 to 60 are represented. The age profile looks relatively similar across regions with the exception of South Asia and the Middle East where applicants are somewhat older (see Figure 4). This might be a problem if older officials had a systematically different level of education than younger ones do in these regions and the age differences between regions did not reflect differences in the underlying population. If, for example, older officials were systematically worse educated than younger ones and we disproportionally sample older ones, then we might underestimate the average educational attainment in those regions. While we cannot completely exclude such a possibility and we have no way to check whether regional sample differences in terms of age reflect underlying population differences it is reassuring that age is not a strong predictor of educational attainment. Therefore, even if we do introduce some sort of bias due to the different age sampling between regions then these biases are likely to be quite small and should not affect our results in a significant way.

Figure 5 shows that the male to female ratio is roughly 2 to 1 in our sample. Females are thus underrepresented. While this underrepresentation is a potential source of concern from a normative standpoint, there is a priori no reason to believe that those patterns in our sample are not representative of the underlying population of civil servants.

Conceptually, there are two potential sources of selection bias in the type of officials represented in our sample. First, a potential source of selection bias could originate from the way the IMF selects participants. Indeed, the selection process of participants in IMF capacity building activities usually takes into account the relevance of the applicant's educational background and professional experience with respect to the specific type of training activities she/he has applied for. We do not consider this potential bias as a source of concern. The reason is simply that our sample comprises all applicants and not solely officials selected for participation in a capacity building activities. One could still argue that our pool of applicants may not be representative of the overall population of civil servants in public administration because not all civil servants are interested in participating in training activities. While it is difficult to refute categorically such claim, we believe that civil servants are in general interested in taking part in training activities even if they would apply simply to alter their daily routine.

Second, another source of selection bias could stem from the screening process operated by domestic authorities. Most training activities are open to spontaneous applications but some others require a nomination by the domestic authorities. To explore whether this potential source of bias is relevant, we check whether the age distribution is different depending on the nature of the application process. We do not have the historical record as to whether a specific IMF training activities was open to spontaneous application or required a nomination, but we know that activities taking place at IMF headquarters are exclusively by application. We thus compare the age distribution of applicants to headquarter activities (spontaneous applications) to the age distribution of applicants for non-headquarter activities who were for the most part nominated by their domestic authorities. As shown in Figure 6, the age distributions across 
those two sub-samples are virtually identical. This suggests that there is a priori no reason to worry about a potential bias stemming from the nature of the application process to IMF training activities and that our sample could be deemed as representative bearing in mind the qualifications on the scope of our dataset discussed earlier.

\section{OUR MEASURE(S) OF EDUCATION ATTAINMENT IN PUBLIC ADMINISTRATIONS}

In the following, we present two measures of education attainment in public administrations namely non quality adjusted and adjusted education attainment measures. We discuss regional differences in those measures and further explore regional differences in educational attainment along gender and seniority.

\section{A. Non quality adjusted measure of education attainment}

A striking observation following the tabulation of CVs of applicants to IMF training activities is that most of the officials surveyed have higher education degrees including in low-income countries. Figure 7 shows that the ratio of officials with a higher education degree is on average close to 1 for all regions. This is in sharp contrast with the large difference in the education attainment in the general population. Overall, we find that the differences in general education attainment in the general population do not necessarily translate into differences in the education attainment in public administrations. Figure 8 shows that the ratio between the fraction of officials with tertiary education in public administrations over the fraction with tertiary education in the general population can be quite large for regions such as Sub-Saharan Africa and Latin America.

To compute our measure of education attainment we attributed a numeric value to each official's highest degree where the numeric value represents the number of years of tertiary education. For instance, a high school degree (irrespective of the country where the degree was awarded) will take a value of zero while a $\mathrm{PhD}$ degree (irrespective of the country where the degree was awarded) will take a value of 9 . We then simply average those numerical values by country and region. Figure 9 shows that there are little differences in the average number of years civil servants have spent in higher education across regions. This confirms again that general population education attainment does not translate into similar differences in public administration attainments. Those differences may stem from labor market duality and lack of private sector employment opportunities for educated individuals in less advanced countries.

\section{B. Quality adjusted education attainment in public administrations}

The literature on education and labor markets has used various ways to adjust existing measure of education attainment for quality. The most widely used way to assess the marginal return to schooling and hence a way to get at education quality is the use of so- called Mincerian equations. Those equations allow an assessment of the return to schooling either at the micro level using wage series or more crudely at the macro level by estimating production functions to back out the return to education in various countries. For the purpose of this paper, even if wage series would be available for a large number of countries, it is hard to conceive that anything meaningful would come out of using Mincerian equations given the way in which compensation schemes are designed in most public administrations. Estimating a production 
function and possibly incorporating the public sector to back out the return to education in public administrations is potentially an interesting avenue which we leave for future research.

More recently, the literature on education has used test scores such as Program for International Student Assessment (PISA) to adjust existing measures by quality. While those test scores are potentially appealing, they are so far limited to high school students and the geographical scope is still limited to mostly OECD countries. Indeed, as discussed earlier, most of the civil servants surveyed in our sample have a higher education degree. It would thus be insufficient to use high school test score to adjust their overall education attainment solely by the quality of the high school system in the country where they graduated.

In this paper, we instead choose to use a country-level academic ranking to weigh the number of years of tertiary education of public official. Specifically, we use a Shanghai University League Table based country wide academic ranking computed by Universitas, a global network of universities. Universitas' ranking complements the Shanghai score with other measure of academic performance of universities present in a given country. One may argue that it is quite restrictive to focus solely on academic standards to adjust for quality of education attainment. The ranking thus also takes into account the market value of a higher education degree by using measure of unemployment rate for individuals holding a higher education degree (see Appendix). ${ }^{2}$ According to this overall ranking of 48 countries, the United States ranks first, the United Kingdom second, Canada third and Indonesia forty eighth. When exploiting the information regarding where officials surveyed have studied, we find that, outside advanced countries, East Asia and Central and Eastern Europe have the largest share of officials having studied in one of the top 48 countries ranked for its academic standards as shown in Figure 10.

To construct the quality adjusted measure of education attainment we simply compute a weighted average of the number of years of educations using the country academic ranking as weights. This measure of adjusted education attainment for country $i$ formally rewrites as follows:

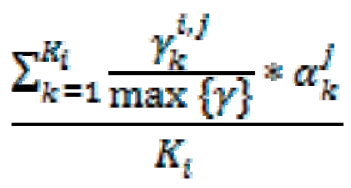

$\gamma_{k}^{i, j}$ is the years of tertiary education of individual $k$ who works in country $i$ and studied in country $j$

$K_{i}$ is the total number of individuals from country $i$ in our sample

$\alpha_{k \text { is }}^{j}$ the weight of the country $j$ in which individual k studied

\footnotetext{
${ }^{2}$ As discussed in the introduction other inputs such as capital inputs and organizational factors may play a key role in determining the actual effectiveness of public administrations. We here focus on the specific quality of human capital input into the public administration.
} 
By dividing the product between the number of year of education and the country wide academic score by the highest number of years of education $\max \gamma$ (in our case effectively 9) our measure of education attainment in public administration is normalized to 1 . Since we then multiply this normalized score by a weight between 0 and 1 the final measure also lies between 0 and 1. Particularly it takes a minimum value of 0 if all officials have a high school degree only and takes a maximum value of 1 if all officials have a US PhD. Figure 11 shows the difference in our adjusted measure of education attainment across regions. The adjusted measure of education attainment is more heterogeneous than the non-adjusted, as shown Figure 12 . This is simply because country academic ranking vary widely and thus countries in which most public servants are exposed to frontier knowledge will achieve a higher overall measure of adjusted education attainments. East Asia now ranks second behind advanced countries and is followed by Central and Eastern Europe while Central Asia ranks last. The heterogeneity across regions displayed with our adjusted measure is however quite different from the one in general population's education attainment. Central Asia for instance has a relatively high non adjusted education attainment in both the general population and in the public sector but our adjusted measure shows that education attainment is much lower than in many other regions. Those regional differences should not hide the fact there are important differences within regions, however. Normalizing the regional adjusted score by the variance within region allows to put in perspective average level of education attainment against variability within region. Sub-Saharan Africa is for instance a region where the variability within region is extremely high compared to the average level of education as shown in Figure 13.

\section{Seniority and Gender}

We now turn to explore regional differences in educational attainment along seniority and gender.

\section{Seniority}

We classify officials into two broad categories namely managers and non-managers. The manager group is constituted of officials with a pay grade from division chief upwards. Figure 14 shows that managers are in general more educated than non-managers except for the Middle East and North Africa where managers are on average less educated than nonmanagers. For Central and Eastern Europe, we observe that managers and non-managers have similar education levels. Those patterns are potentially the result of organizational and incentive structure which are worthy of further investigation. A finer categorization of seniority levels reveals interesting patterns in education attainment in public administrations across regions. Figure 15 shows that there is a "missing middle" in other words that education attainment does not increase monotonically with the level of seniority. This is however not necessary a patterns specific to developing countries and is true for most regions.

\section{Gender}

Using our adjusted measure of education attainment in public administrations, Figure 16 shows that female education attainment is more or less at par with that of male officials but 
female officials constitute a much smaller fraction of civil servants than male officials. This was already reflected in the discussion above where we showed that the number of female officials in our sample is half that of male ones. Central Asia and Central and Eastern Europe constitute two notable exceptions. Indeed, in the latter two regions there seem to be as many women as men employed in the public sector. Looking at a breakdown of the gender ratio by seniority Figure 17 shows that female officials constitute a small share of managers except in Central and Eastern Europe. Figure 18 further show that female officials constitute an even smaller share of the senior management in all regions without exceptions. Those observations suggest that those women who are hired are as educated as their male colleagues, but less women than men are hired and even less are promoted to senior management positions.

\section{Agency}

We further explore whether education attainments differ across agencies. Figure 19 shows that contrary to the commonly held premise in the economics profession, central bank staff is not necessarily more educated than staff at other agencies such as ministries of finance and economies except in advanced countries.

\section{Applications}

In the following, we explore a few interactions using our new dataset which can help inform the debate on two important fronts. First, our dataset can help shed light on the role of incentive structures in public administrations in attracting well educated officials. This relates to the literature on labor market rigidity and civil service reforms. Delfgaauw and Dur (2008) study optimal incentive contracts for public sector workers in order to attract dedicated staff under different informational assumptions. Rama (1999 and 2006) and Clements et al. (2010) study international experiences with wage structure and separating contracts to reduce budget deficits and address public sector inefficiencies. Second, our dataset can help us in exploring whether a more educated workforce in public administrations may affect government effectiveness including through tax revenue mobilization, limiting corruption, public financial management and support for markets.

\section{A. About Incentives}

We explore whether the wage difference between the public administration and other employment sectors is statistically associated with the level of education in the public administration. The left hand side of panel Figure 20 displays the cross-correlation of wage differences between the public administration and the manufacturing sector and our measure of the level of education attainment in public administrations. We observe no statistically significant association. The right hand side of Figure 20 shows the cross-correlation of the wage difference between the public sector and the financial sector and our measure of education attainment. We observe that education attainment in public administrations is positively and statistically significantly associated with the difference in wages between the public administration and the financial sector. In other words, the better public sector pay relative to wages in finance the higher the level of education of public sector officials. This higher sensitivity of education attainment in public administrations to the wage gap between public administration and the financial sector could be explained by the fact that the latter 
sector constitutes the main outside option for civil servants in central banks and ministries of finance and economies.

\section{B. About government effectiveness}

In the following, we explore whether higher education attainment in public administrations is associated with higher tax revenue mobilization. Revenue mobilization is one of the biggest challenges for developing countries. As pointed out by Besley and Persson (2006), a higher revenue mobilization should be seen not as a source of distortions but rather as a sign of state capacity and state building for developing countries. Figure 21 displays the cross-correlation between our measure of education attainment and tax revenue over GDP. The association is positive and statistically and economically strong. Figure 22 further shows that this association remains positive and significant even after controlling for the level of GDP per capita and the level of education in the general population.

We further explore whether higher education attainment in public administrations is associated with limiting corruption in those administrations. Figure 23 shows the cross-correlation between our measure of education attainment in public administration and an indicator of corruption based on PRS Group 2012 data. We observe a negative and statistically significant relationship between corruption and education attainment in public administration. Figure 24 also shows that education attainment is negatively associated with corruption even when controlling for the effect of GDP and education in the general population. This finding could suggest that a more educated work force in public administration may contribute to foster accountability and limiting corruption in public administrations. More work is of course needed to establish a causal relationship.

We further explore the cross-correlation between our measure of education attainment in public administration and respectively a composite indicator of public financial management obtained from the World Bank (2012) and an indicator of bureaucratic Quality obtained from PRS Group (2012). Both Figures 25 and 26 shows a positive and statistically significant association between our measure of education attainment and these two measures of government effectiveness. Those findings are robust to controlling for the effect of GDP and the level of education in the general population.

Another dimension of government effectiveness is reflected in the ability for government to support the development, regulation and supervision of private markets such as domestic financial sector. Figure 27 shows the association between our measure of education attainment in public administration and a composite index capturing domestic financial sector standards including regulation, supervision, competition... We find a positive and a statistically and economically significant relationship between those two measures. This finding could suggest that a more educated workforce in public administration help raise the standards of domestic financial sector. This finding certainly echoes the debate over the fact that regulatory bodies often lag behind private financial firm in terms of attractiveness of talent and fall back when it comes to keeping up with financial innovation originating from the private sector. 


\section{Conclusions}

In this paper, we have described a novel dataset on education attainment in public administrations which allows for important new insights. Importantly we show that there are significant differences between education attainment in the general population and education attainment in public administrations. Caution should thus be taken in using education attainment in the general population as a proxy for education attainment in public administrations when trying to answer questions relating to state capacity. This dataset may allow to address some of those questions much more directly and opens new avenues for future research on the importance of human capital in the public sector. In this paper, we have explored a few important applications to help understand issues of government effectiveness and labor market issues in general. More needs to be done to explore more systematically each of those applications.

To get a fuller picture of what contributes to government ineffectiveness, one would also need to go beyond documenting the characteristics of inputs that go into public administration to document the differences in organizational structure in public administrations. We know very little about the latter but it is likely to play a key role in setting incentives and creating a wellfunctioning public sector. Building on the paper by Chong and others it would also be useful to build a dataset for lower level officials (e.g. tax collectors) to complement our dataset. Putting everything together, it would then be possible to study how the interplay between human capital at all levels of seniority and the organizational structure of public administrations determines government effectiveness. 


\section{REFERENCES}

Andrews, Matt, Lant Pritchett and Michael Woolcok, 2012, "Escaping Capability Traps through Problem-Driven Iterative Adaptation (PDIA)," Working Paper no. 299, Center for Global Development, Washington DC.

Arezki A., A. Dupuy and A. Gelb, 2012, "Resource Windfalls, Optimal Public Investment and Redistribution: The Role of Total Factor Productivity and Administrative Capacity," IMF Working Paper no. 12/200, International Monetary Fund: Washington DC.

Barro Robert J. \& Lee Jong-Wha, 2010, "A New Data Set of Educational Attainment in the World, 1950-2010," NBER Working Papers 15902, National Bureau of Economic Research, Cambridge.

Baunsgaard, Thomas \& Michael Keen, 2010, "Tax revenue and (or?) trade liberalization," Journal of Public Economics, Elsevier, October, Vol. 94(9-10), pp. 563-577.

Besley, Timothy, 2006, "Principled Agents? The Political Economy of Good Government," The Lindahl Lectures, Oxford University Press.

Besley, Timothy and Torsten Persson, 2009, "The Origins of State Capacity: Property Rights, Taxation and Politics," American Economic Review, Vol. 99(4), pp. 1218-44.

Besley, Timothy, Jose G. Montalvo \& Marta Reynal-Querol, 2011, "Do Educated Leaders Matter?," Economic Journal, Royal Economic Society, Vol. 121(554), pp. F205-08.

Botero, Juan, Alejandro Ponce \& Andrei Shleifer, 2012, "Education and the Quality of Government," NBER Working Papers 18119, National Bureau of Economic Research, Cambridge.

Chong, Alberto, Rafael La Porta, Florencio Lopez-de-Silanes \& Andrei Shleifer, 2012, "Letter Grading Government Efficiency," NBER Working Papers 18268, National Bureau of Economic Research, Cambridge.

Clements B., Gupta S., Karpowicz I., and S. Tareq, "Evaluating Government Employment and Compensation. Technical Notes and Manuals," Fiscal Affairs Department, International Monetary Fund.

Heston, A., R. Summers and B. Aten, 2009, "Penn World Table Version 6.3," Center for International Comparisons of Production, Income and Prices at the University of Pennsylvania, August.

Josse Delfgaauw \& Robert Dur, 2008, "Incentives and Workers' Motivation in the Public Sector,"Economic Journal, Royal Economic Society, Vol. 118(525), pp. 171-191, 01. 
Jones, B. and B. Olken, 2005, "Do leaders matter? National Leadership and Growth Since World War II," Quarterly Journal of Economics, pp. 835-864.

Ostry, Jonathan D., Alessandro Prati \& Antonio Spilimbergo, 2009, "Structural Reforms and Economic Performance in Advanced and Developing Countries," IMF Occasional Paper.

Putnam, R., 1993, “Making Democracy Work: Civil Traditions in Modern Italy,” Princeton, NJ: Princeton University Press.

Rama, Martin, 1999, "Public Sector Downsizing: An Introduction," World Bank Economic Review, Oxford University Press, January, Vol. 13(1), pp. 1-22.

Alvaro Forteza \& Martin Rama, 2006, "Labor Market 'Rigidity' and the Success of Economic Reforms Across More Than 100 Countries," Journal of Policy Reform, Taylor and Francis Journals, Vol. 9(1), pp. 75-105. 


\section{Appendix: Country Academic Ranking}

O1: Total number of journal articles produced by higher education institutions

O2: Total articles produced per head of population

O3: Average impact of articles

O4: Weighted Shanghai ranking scores for universities per head of population

O5: Shanghai scores for best three universities

O6: Tertiary enrolment rates

O7: Percentage of population over 24 with a tertiary qualification

O8: Number of researchers in the nation per head of population

O9: Unemployment rate of the tertiary educated compared with school leavers

Source: Universitas (2012)

http://www.universitas21.com/article/collaborations/details/105/measure-4-output 
Figure 1. Education Attainment in the General Population around the World Education Attainment in the General Population around the World

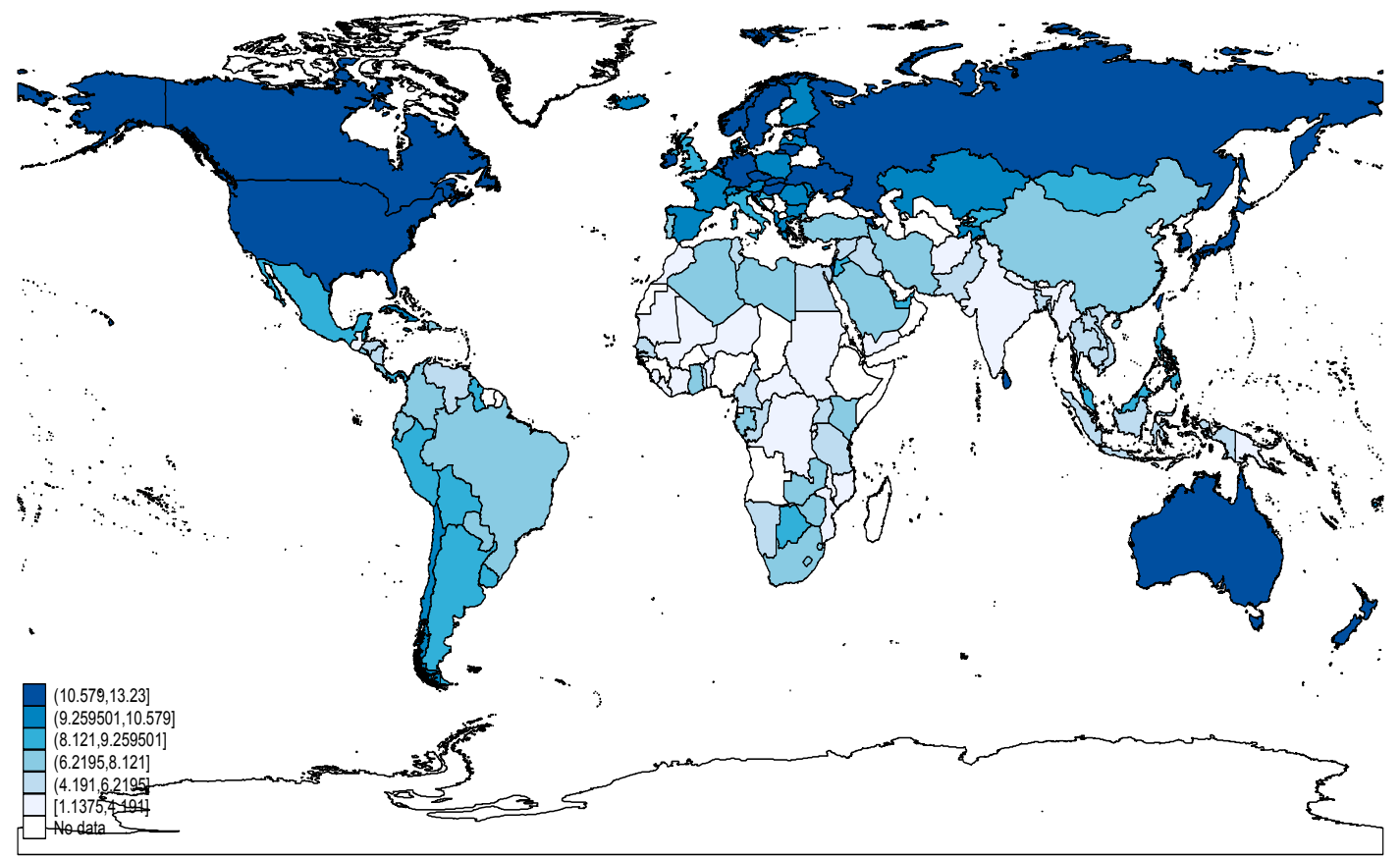

Note: The figure presents the average years of schooling from Barro and Lee (2010).

Figure 2. Example of Official's CV

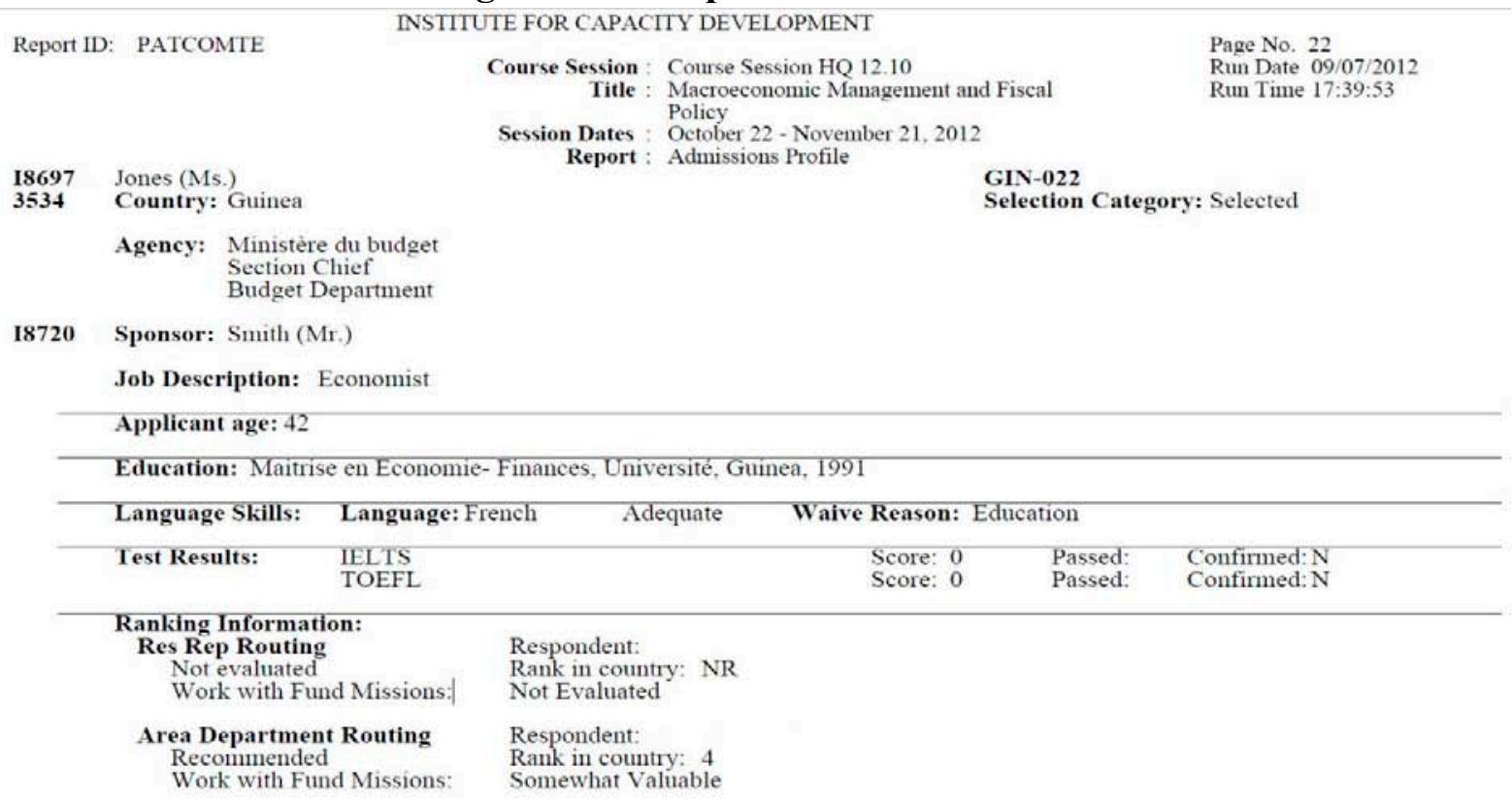

\footnotetext{
Previous applications:
}

Note: The figure presents a standard template from the IMF Institute for Capacity Development Participants and Applicants Database (2012). 
Figure 3. Overview of the Distribution of Age in Sample

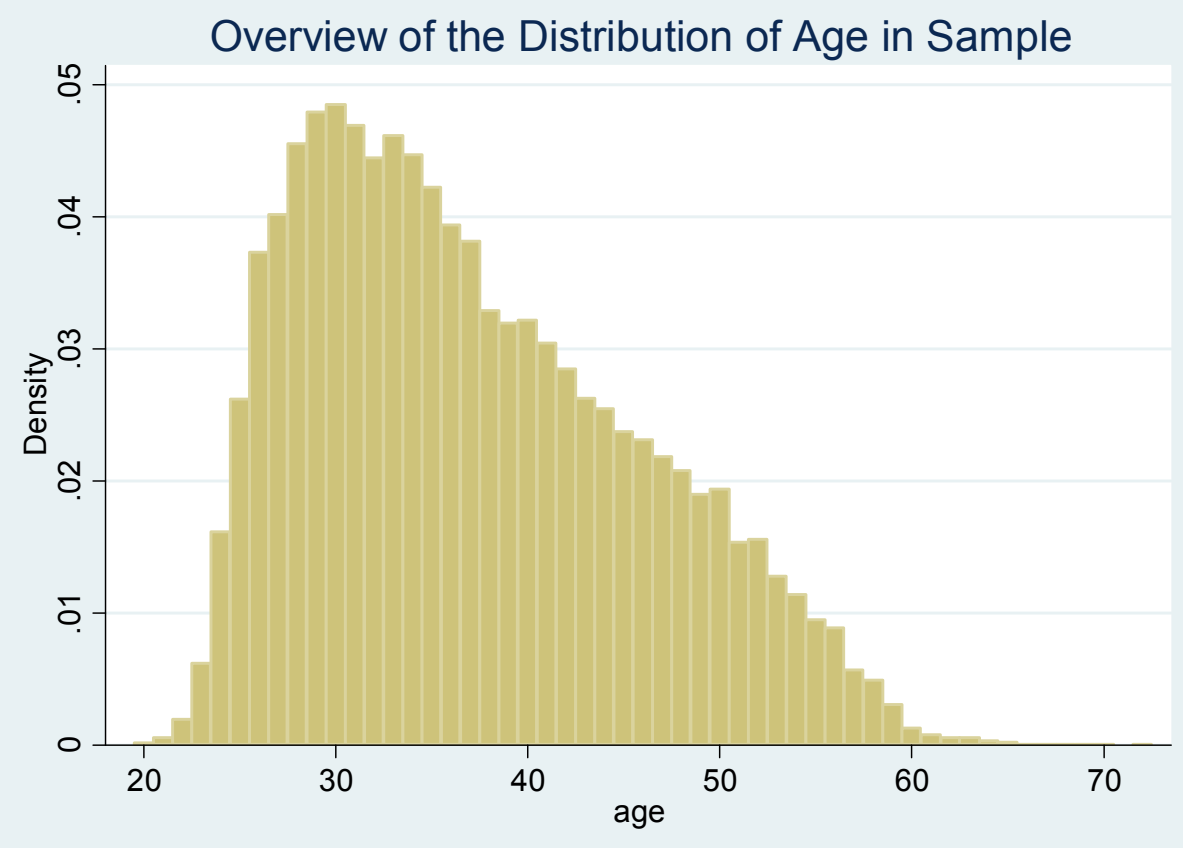

Note: The figure presents the age distribution of applicants to International Monetary Fund training activities during the period 1991-2011.

\section{Figure 4. Age Distribution by Region}

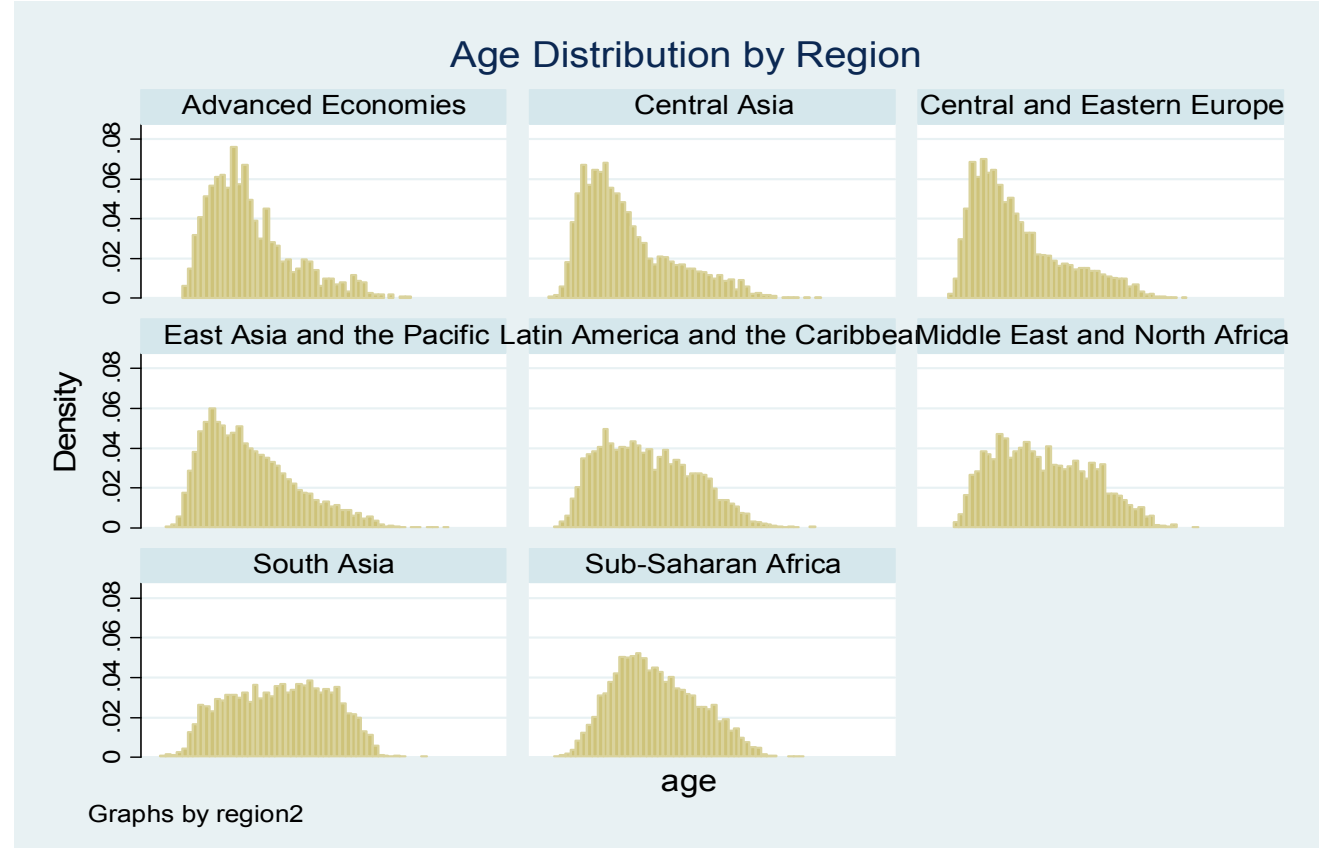

Note: The figure presents the age distribution of applicants to International Monetary Fund training activities during the period 1991-2011 for height different regions. 
Figure 5. Gender Distribution by Region

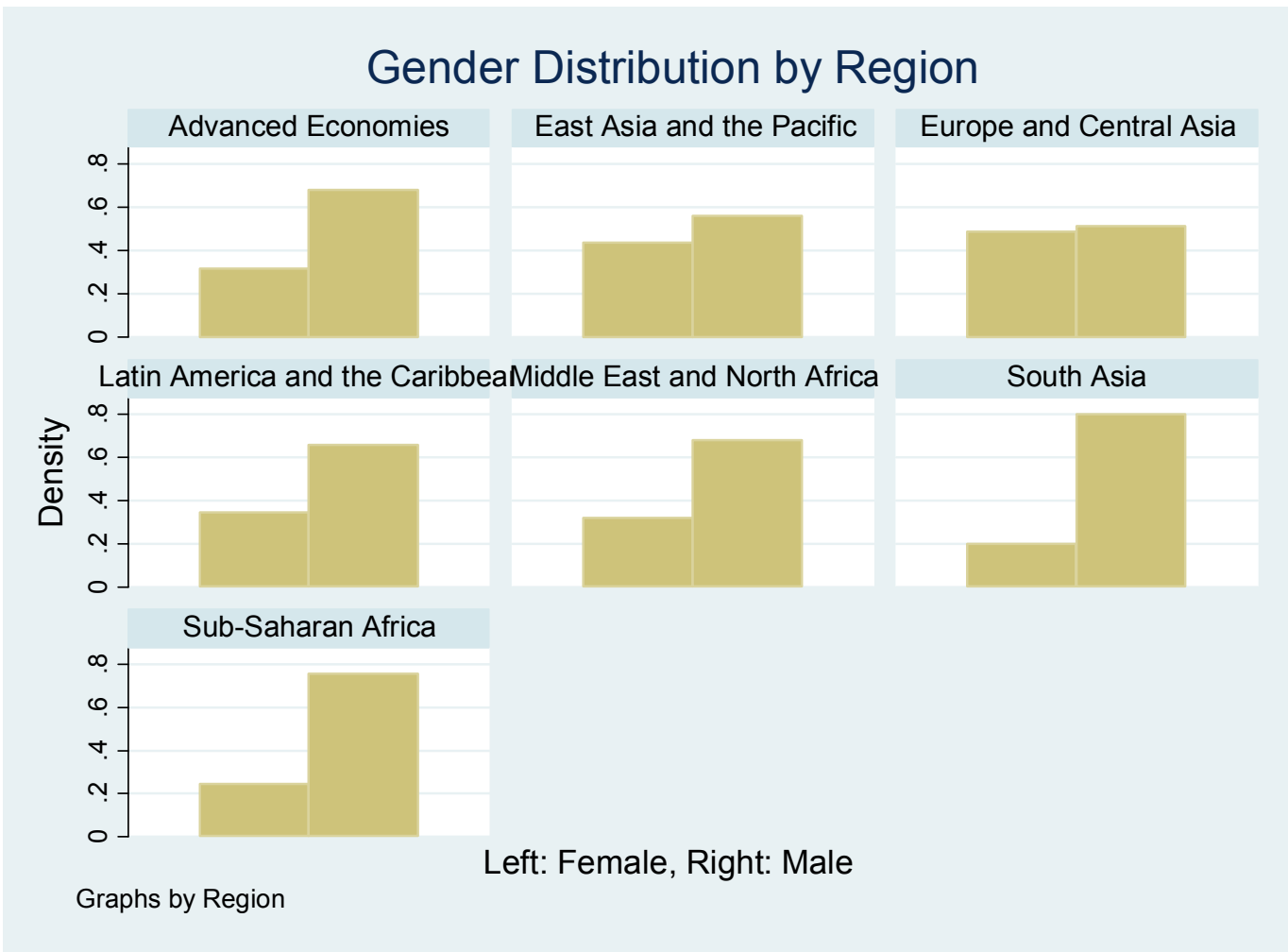

Note: The figure presents the gender distribution of applicants to International Monetary Fund training activities during the period 1991-2011 for height different regions. 


\section{Figure 6. Age Distribution by Type of Course}

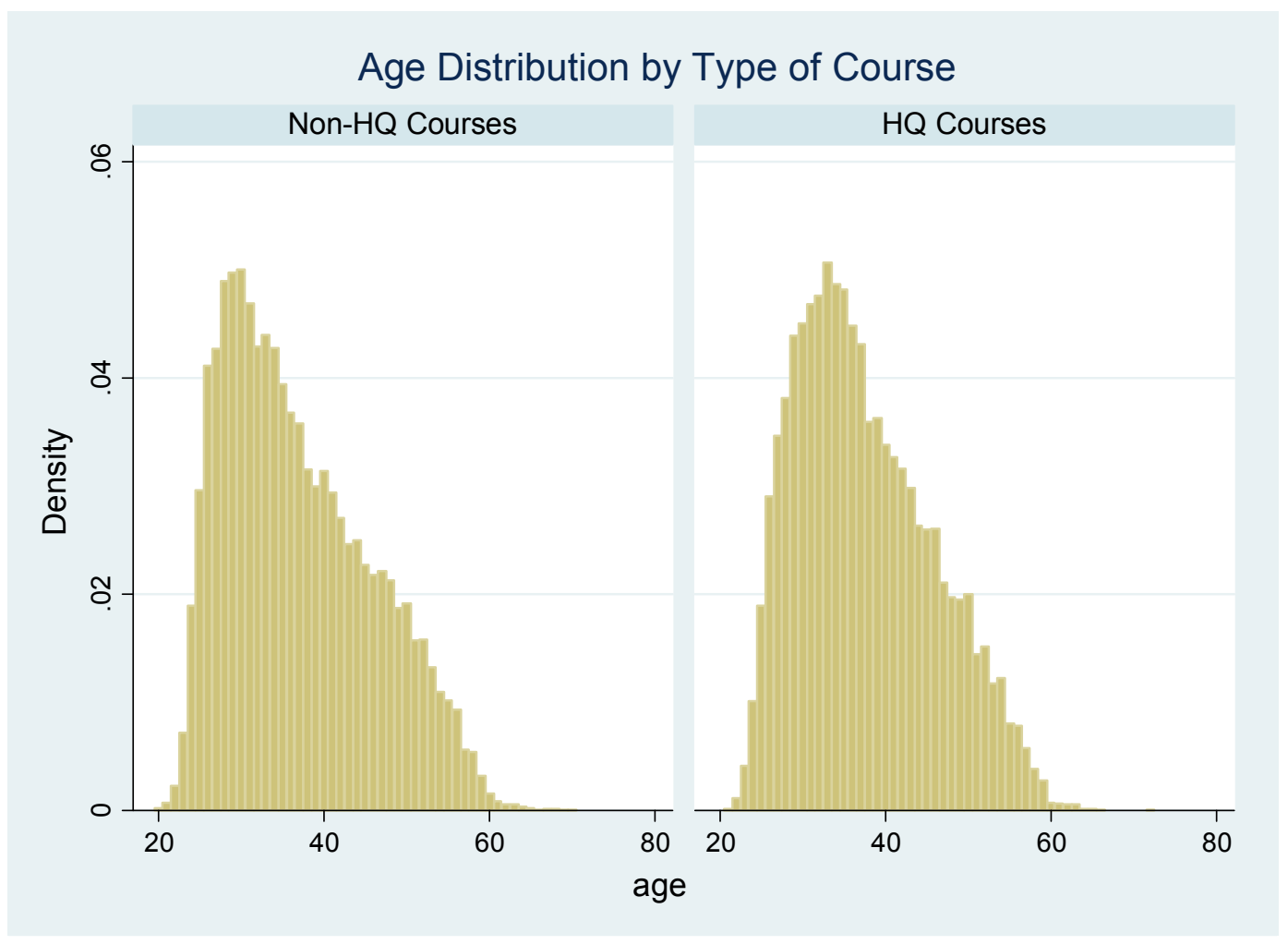

Note: The figure presents the age distribution of applicants to International Monetary Fund training activities during the period 1991-2011 for two different groups namely applicants who applied to non IMF heardquarters (Non-HQ) courses and IMF headquarters (HQ) training activities. Note that training activities at HQ are most exclusively by nomination that is domestic authorities have to formally request their employees in order for the latter to be considered in the associated training activities. In contrast, Non-HQ course are mostly by applications that is civil servants can freely apply to the associated training activities. 
Figure 7. Fraction of Officials with Tertiary Education by Region

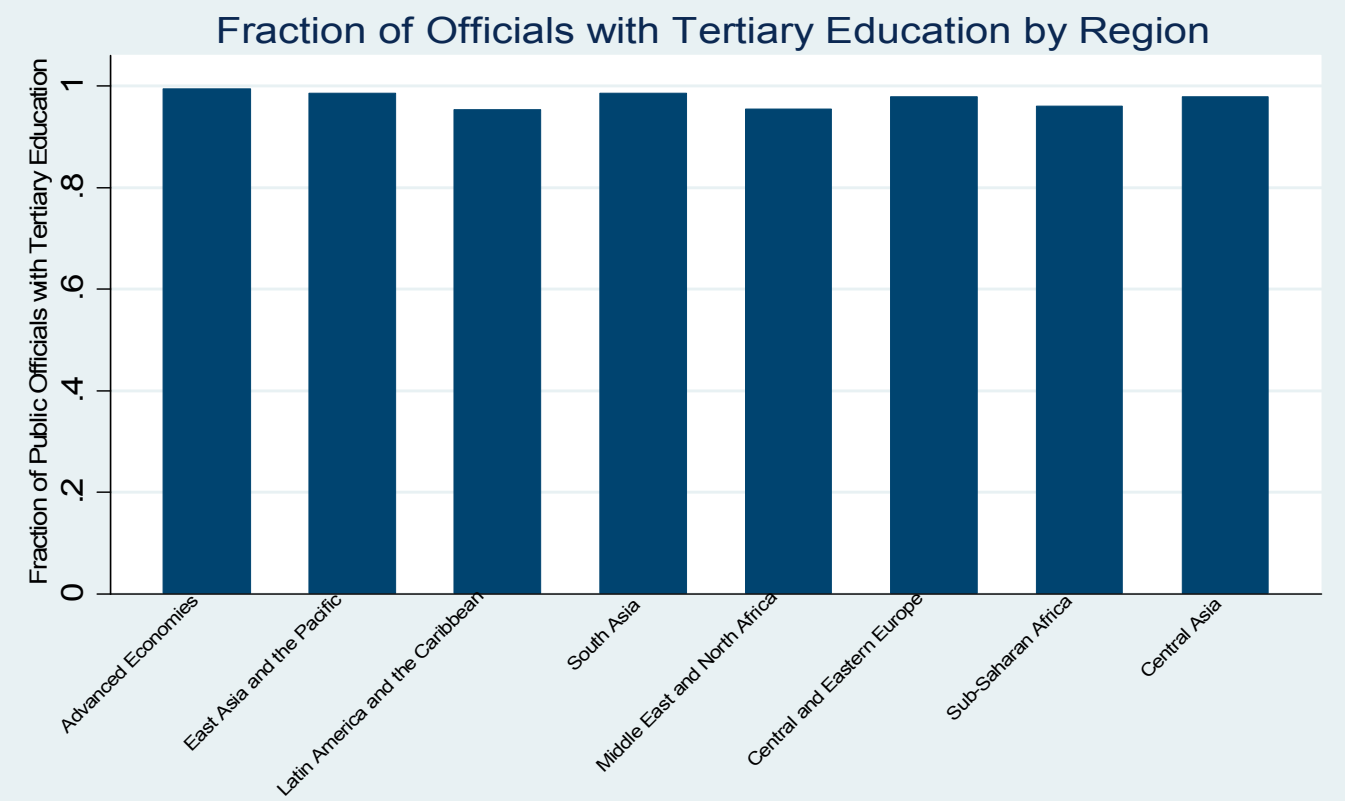

Note: The figure presents the fraction of applicants to International Monetary Fund training activities who hold a tertiary education degree during the period 1991-2011 for eight different regions.

Figure 8. Education Attainments: Public Administration vs. General Population

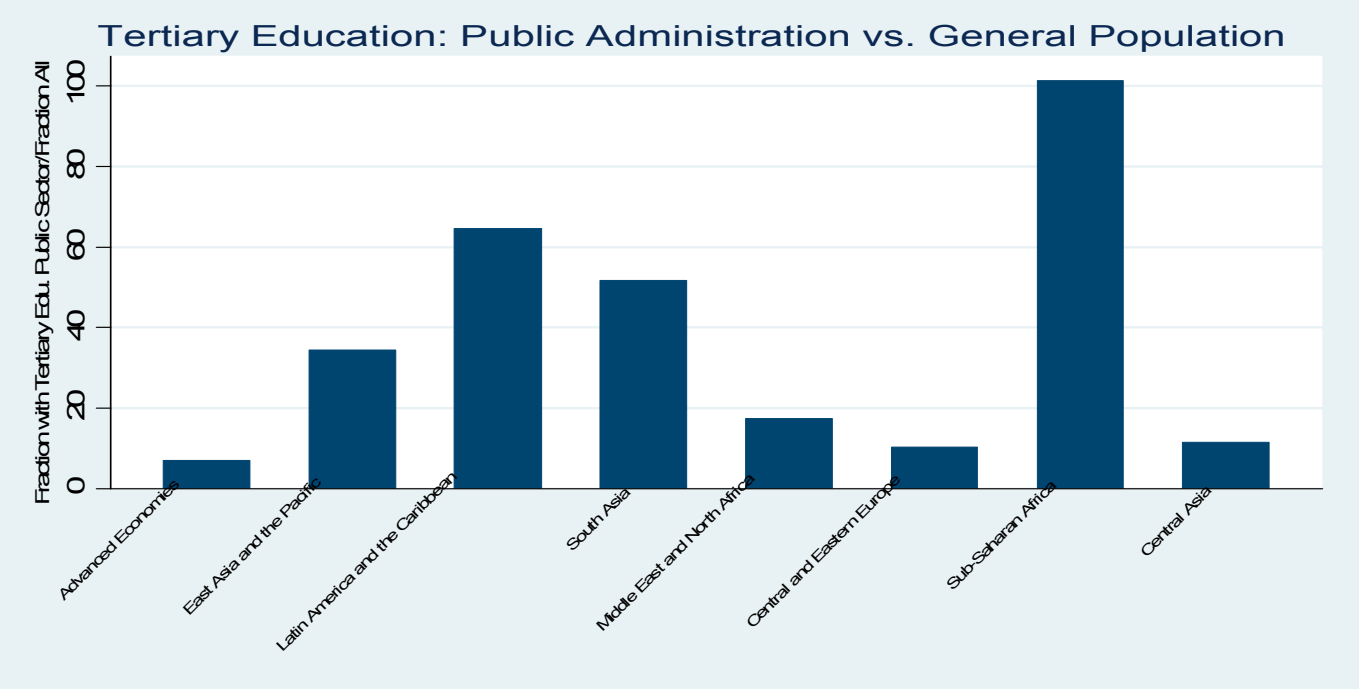

Note: The figure presents the ratio of fraction of applicants to International Monetary Fund training activities during the period 1991-2011 who have a higher education degree over the same fraction for the general population for height different regions. The data on education attainment for the general population are from Barro and Lee (2012). 
Figure 9. Average Years of Tertiary Education in Public Administrations

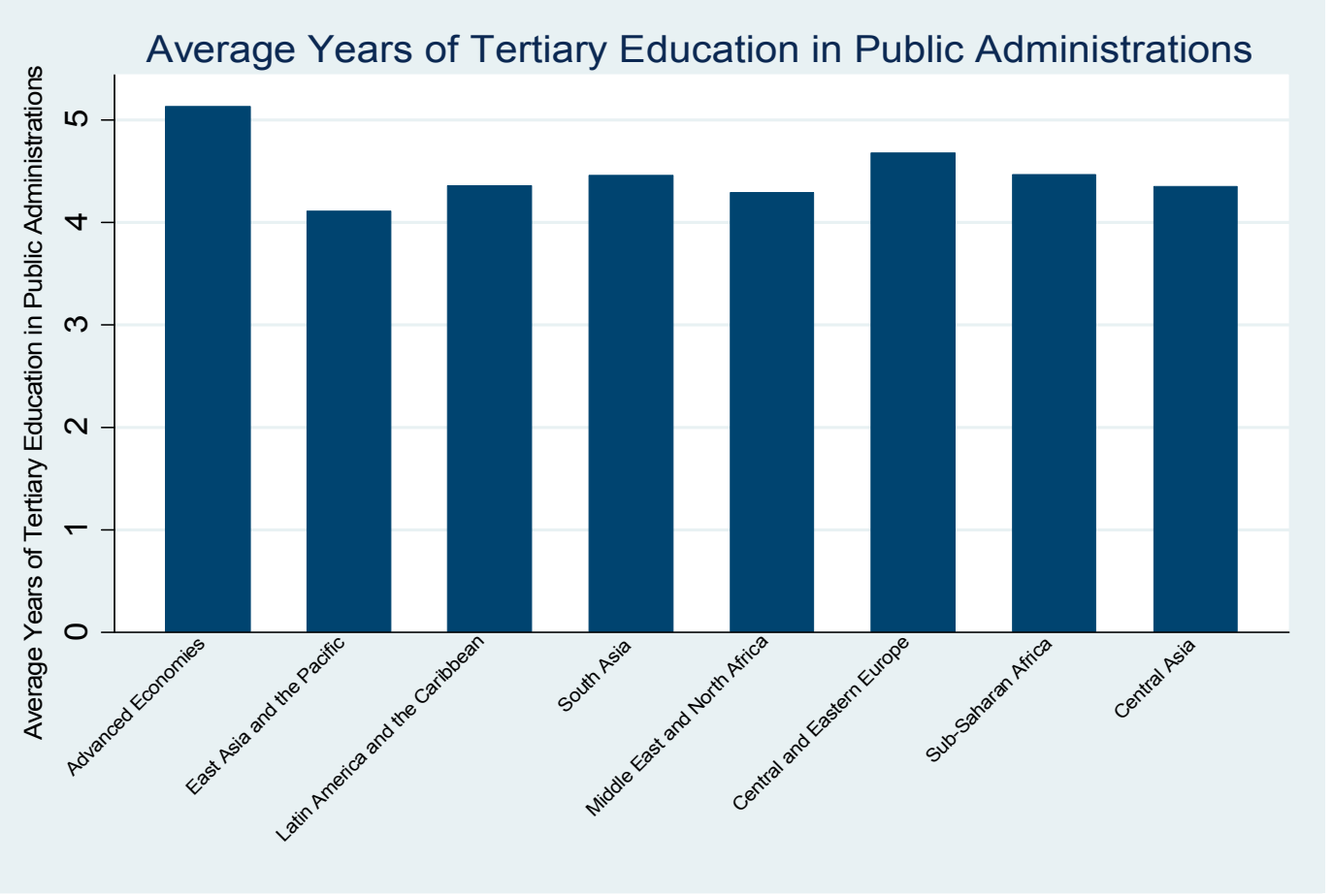

Note: The figure presents the average years of tertiary education of applicants to International Monetary Fund training activities during the period 1991-2011 for height different regions. 
Figure 10. Fraction of officials with a degree from a country ranked in the top 48

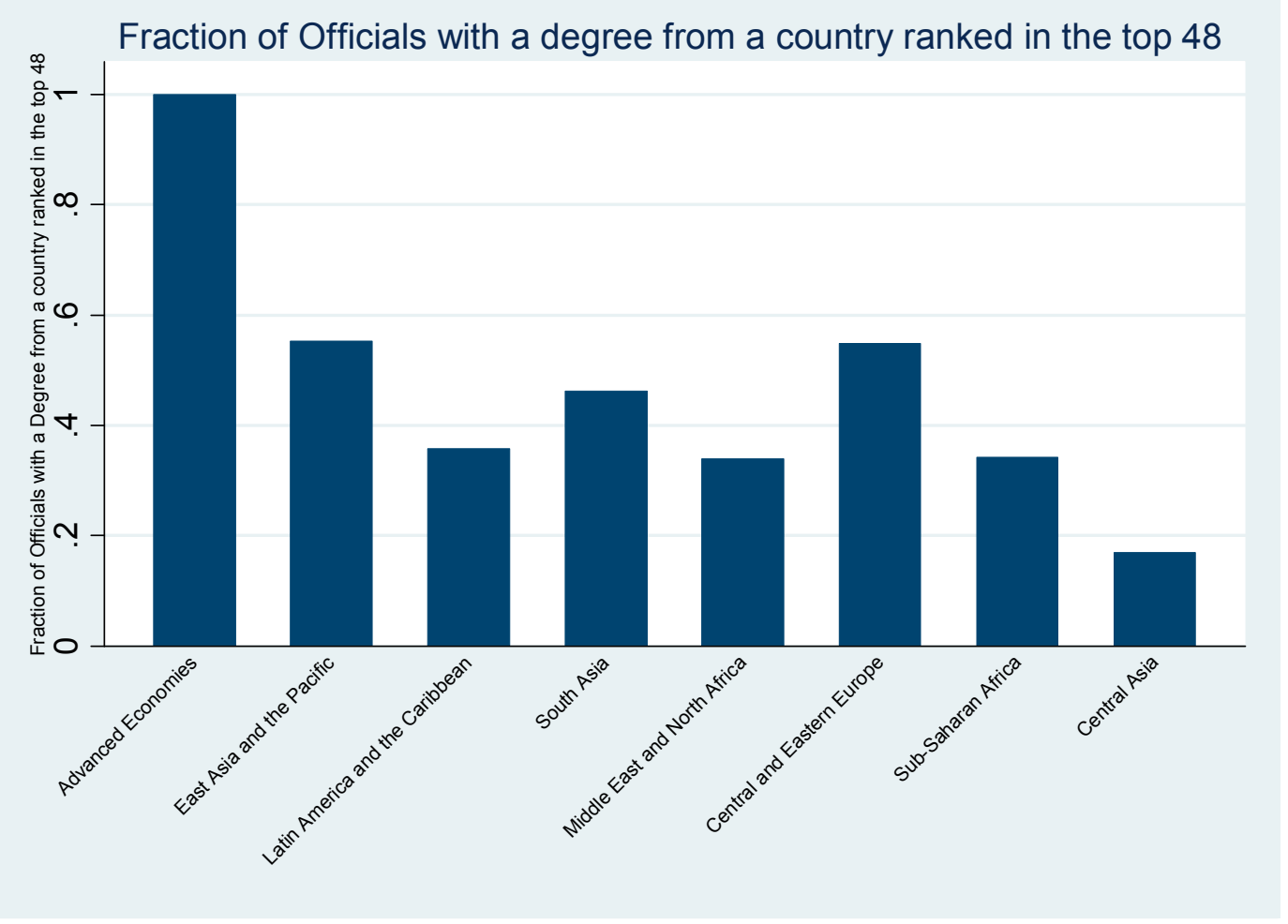

Note: The figure presents the fraction of applicants to International Monetary Fund training activities during the period 1991-2011 who have obtained a degree from a country ranked in the first 48 countries for height different regions. The data is from Universitas website listed below: http://www.universitas21.com/article/collaborations/details/105/measure-4-output 
Figure 11. Normalized weighted years of tertiary education by region

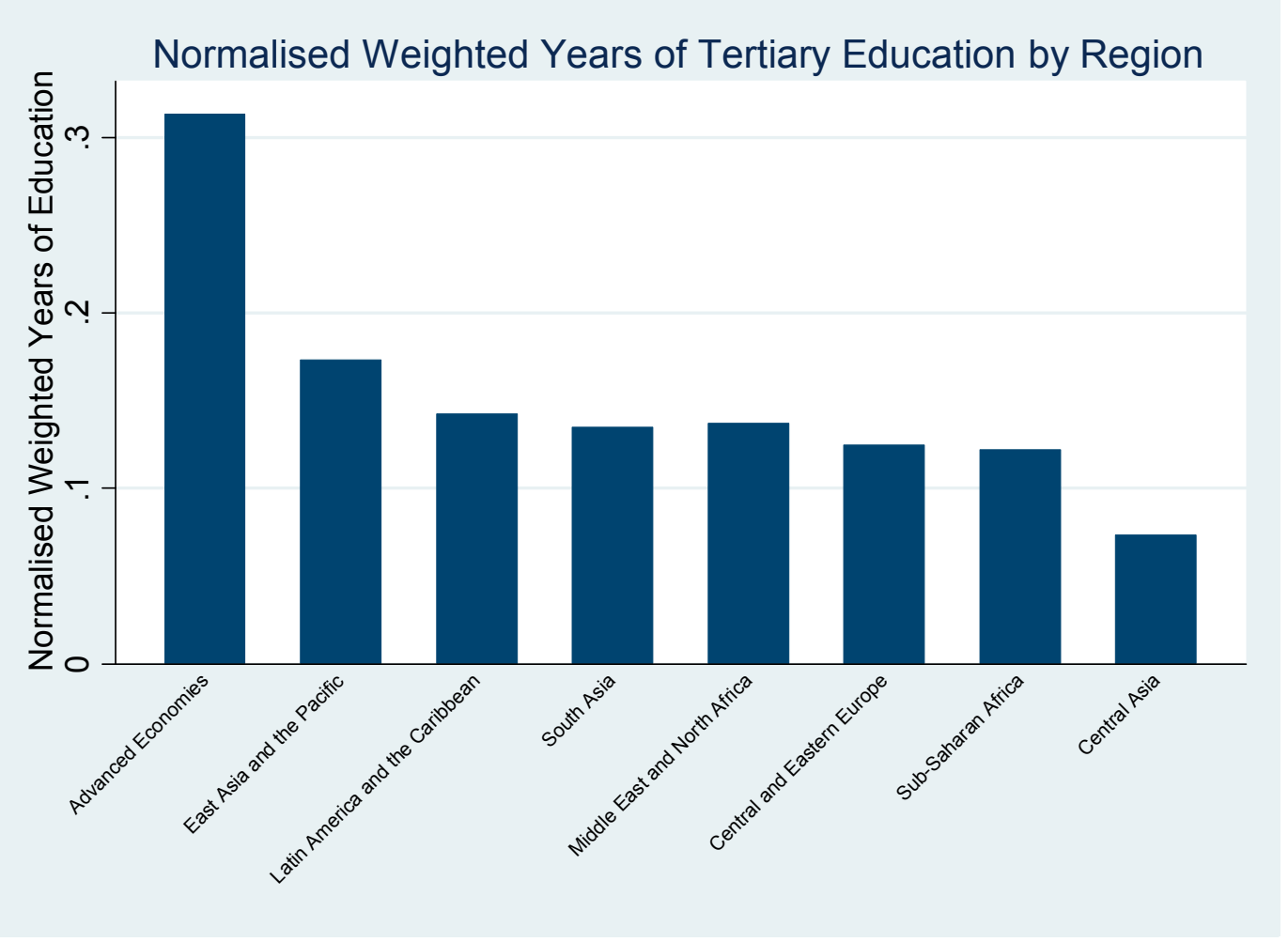

Note: The figure presents our quality adjusted measure of education attainment of applicants to International Monetary Fund training activities during the period 1991-2011 for height different regions. The quality adjusted measure of education attainment is computed as a weighted average of the number of years of educations using a country academic ranking as weights from Universitas (2012). The measure is normalized between $0-1$. The measure takes a minimum value of 0 if all officials have a high school degree only and takes a maximum value of 1 if all officials have a US $\mathrm{PhD}$. 
Figure 12. Adjusted vs. non adjusted education attainment in public administration

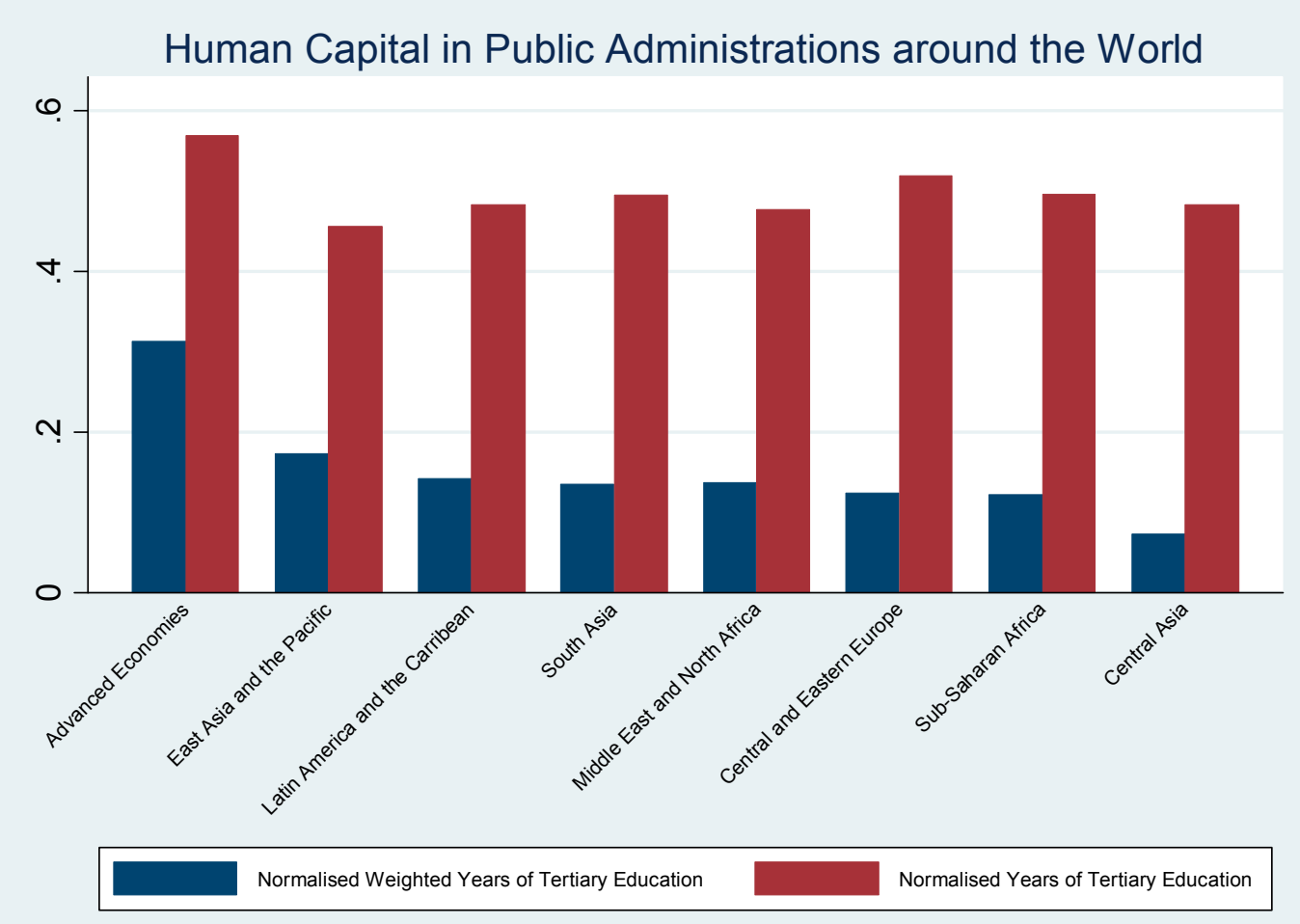

Note: The figure presents our quality adjusted measure (blue bars) and non quality adjusted measure (blue bars) of education attainments of applicants to International Monetary Fund training activities during the period 1991-2011 for height different regions. 
Figure 13. Ratio of public administrations' education attainment in public administrations over associated variance

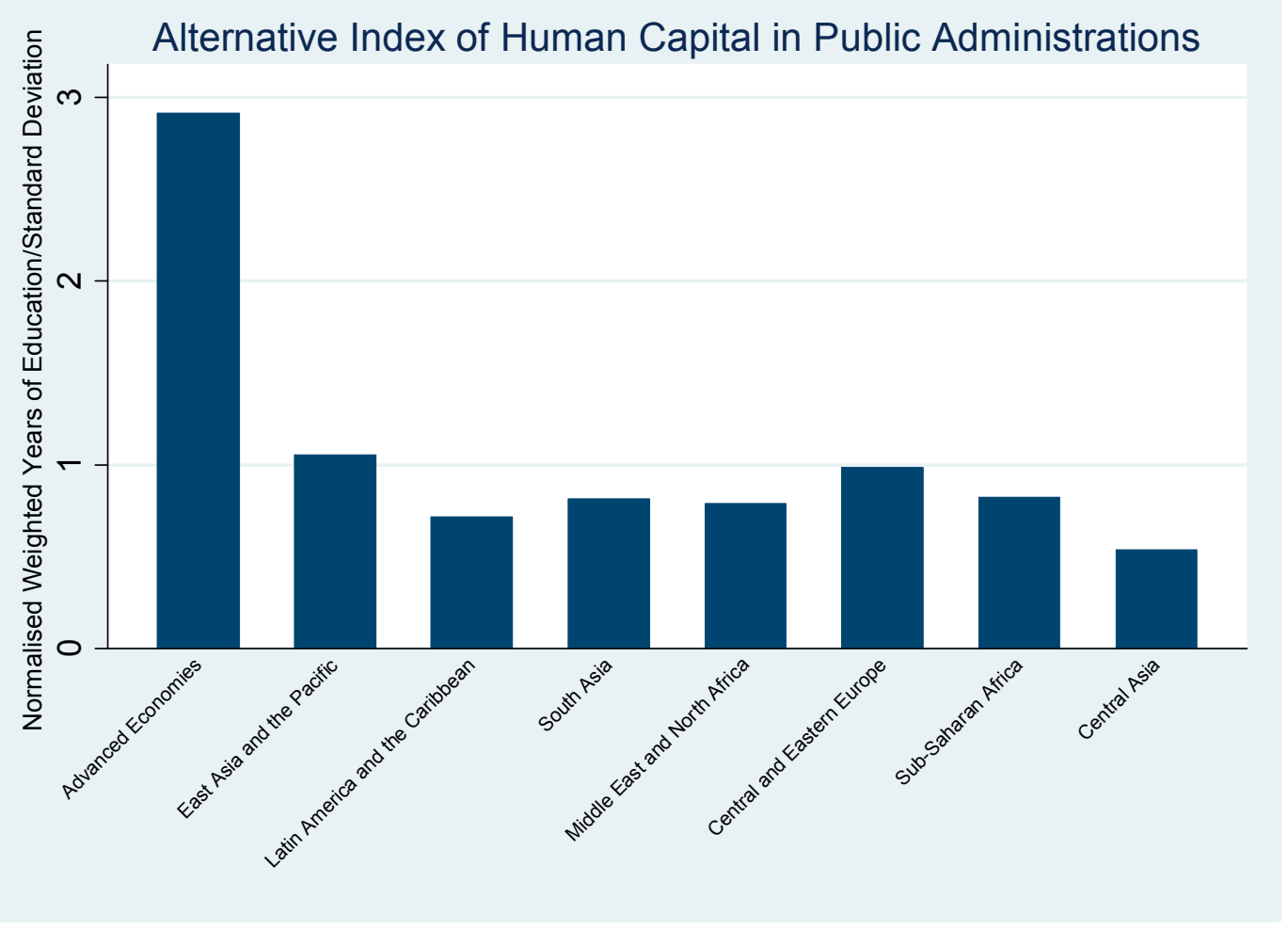

Note: The figure presents our quality adjusted measure of education attainment divided by the variability (proxied by standard deviation) in education attainment within region of applicants to International Monetary Fund training activities during the period 1991-2011 for height different regions. This new measure put in perspective the quality of education attainment with the level of variability within region. 


\section{Figure 14. Education attainment by rank and region}

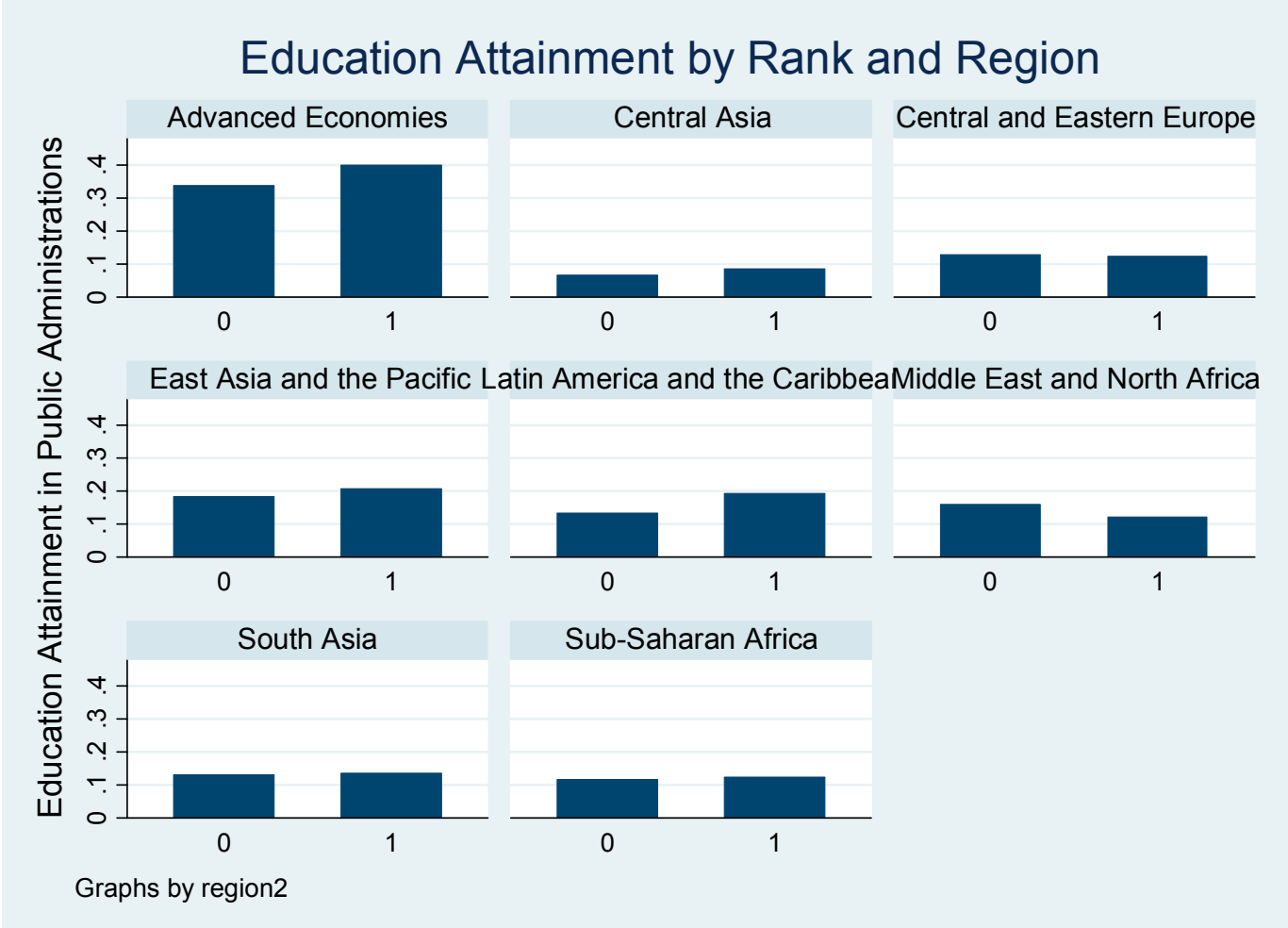

Note: The figure presents our quality adjusted measure of education attainment of applicants to International Monetary Fund training activities during the period 1991-2011 for height different regions. For each region and each panel, the left hand side bar numbered 0 stands for non managers (e.g. analyst, economist, senior economist...) and the right hand side bar numbered 1 stands for managers. 


\section{Figure 15. Education attainment by seniority and region}

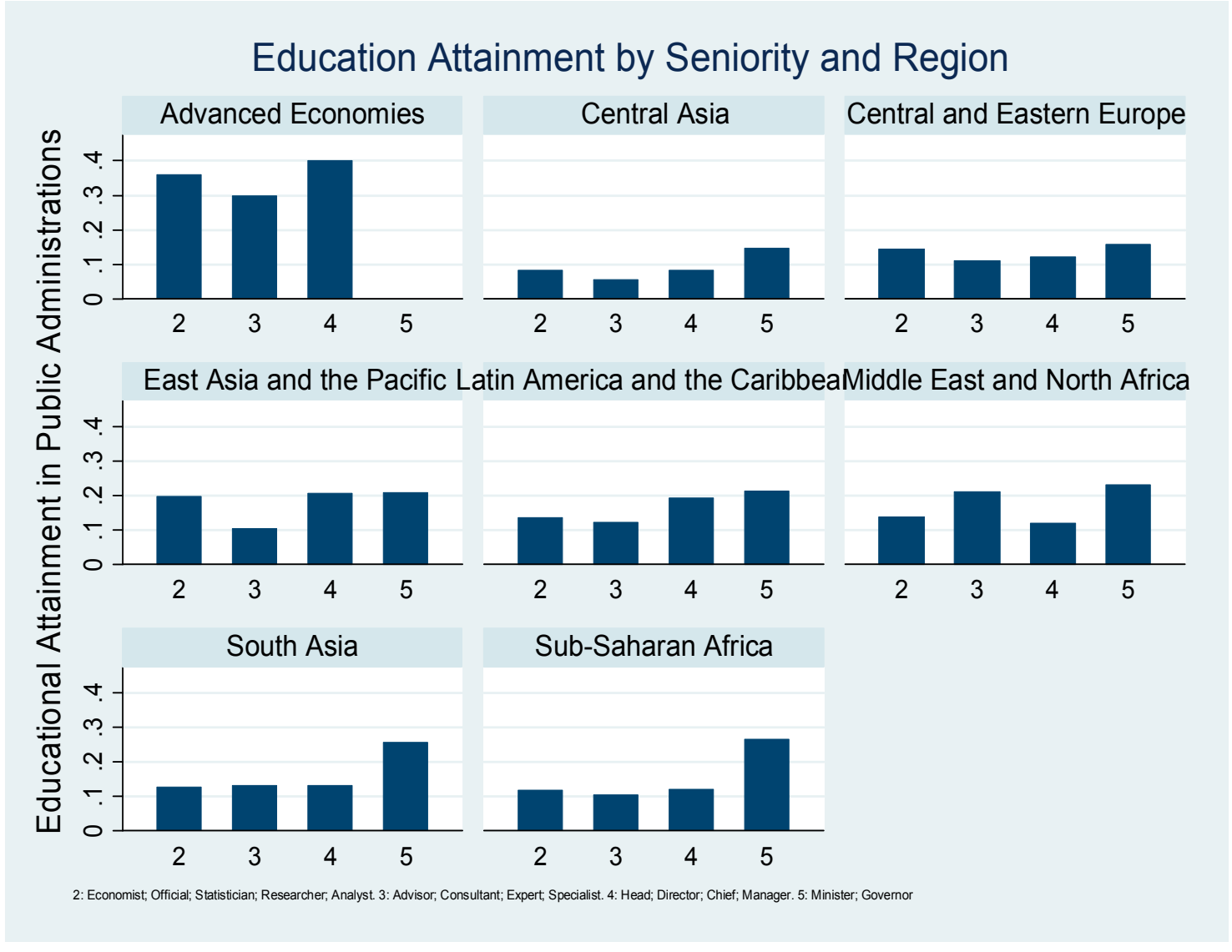

Note: The figure presents our quality adjusted measure of education attainments of applicants to International Monetary Fund training activities during the period 1991-2011 for height different regions. For each region, we present the level of education attainment for several levels of seniority going from 2 to 5 . A higher number stands for higher level of seniority. 
Figure 16. Gender differences in education attainment in public administrations

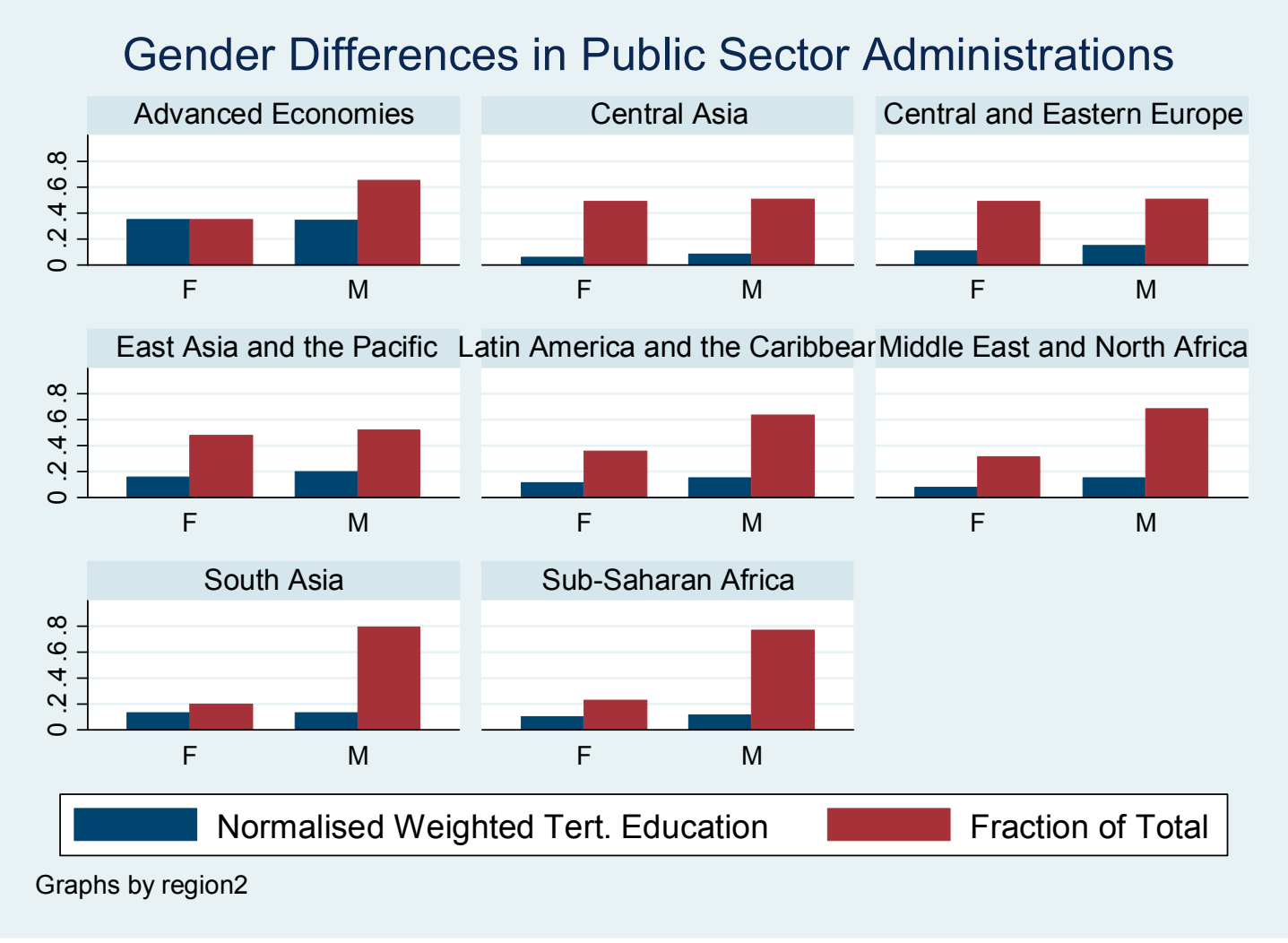

Note: The figure presents our quality adjusted measure of education attainments of applicants to International Monetary Fund training activities during the period 1991-2011 for height different regions. For each region, the figure presents the level of education attainments for female $(\mathrm{F})$ and male (M). For each gender, the left hand side bar is level of education attainment and the right-hand side presents the fraction of the associated gender in our sample of applicants. 
Figure 17. Fraction of Managers who are male

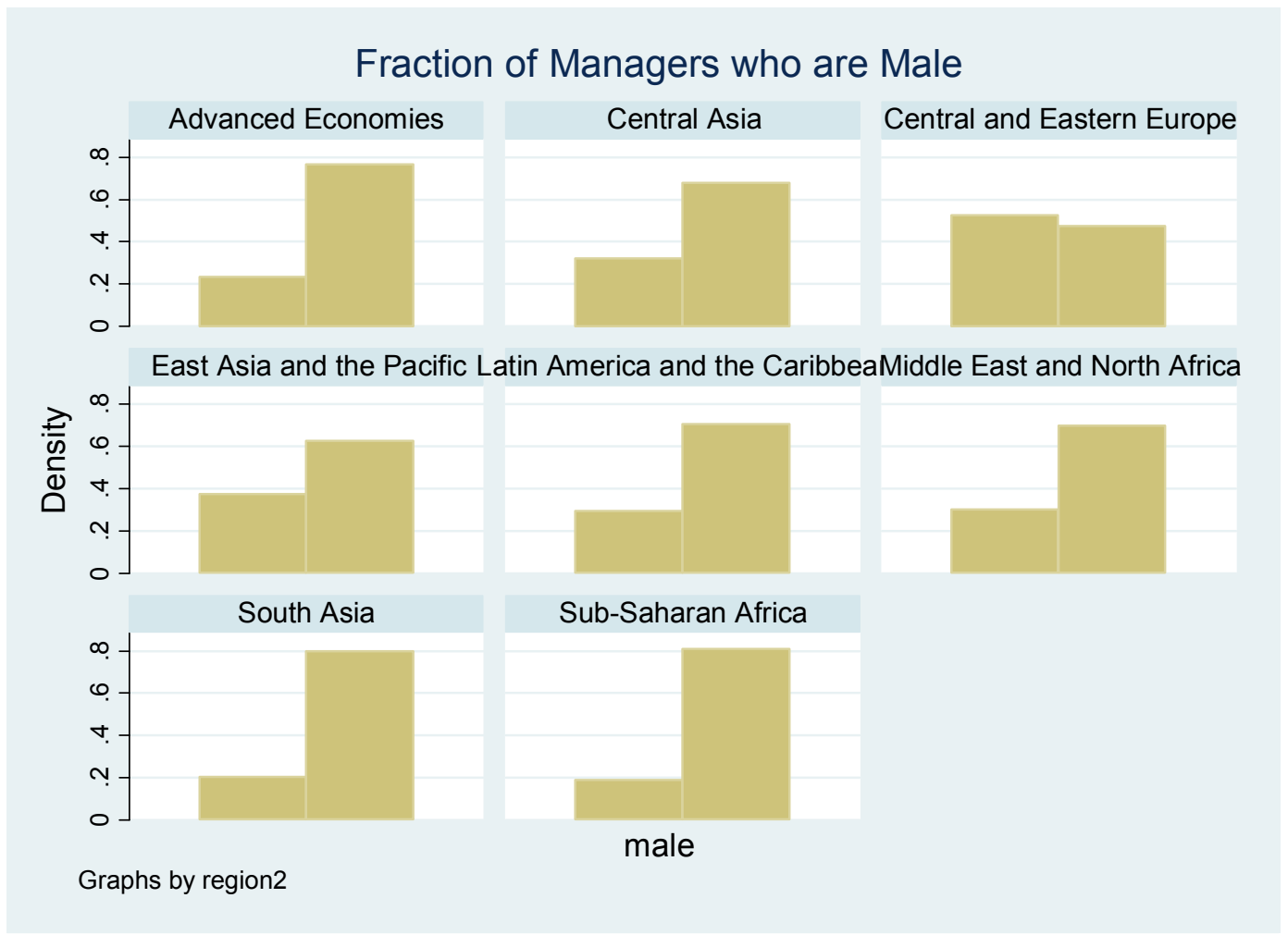

Note: The figure presents the fraction our manager by gender among our sample of applicants to International Monetary Fund training activities during the period 1991-2011 for height different regions. For each region, the figure presents the fraction of female (left hand side) and male (right hand side) manager. 
Figure 18. Fraction of senior managers who are male

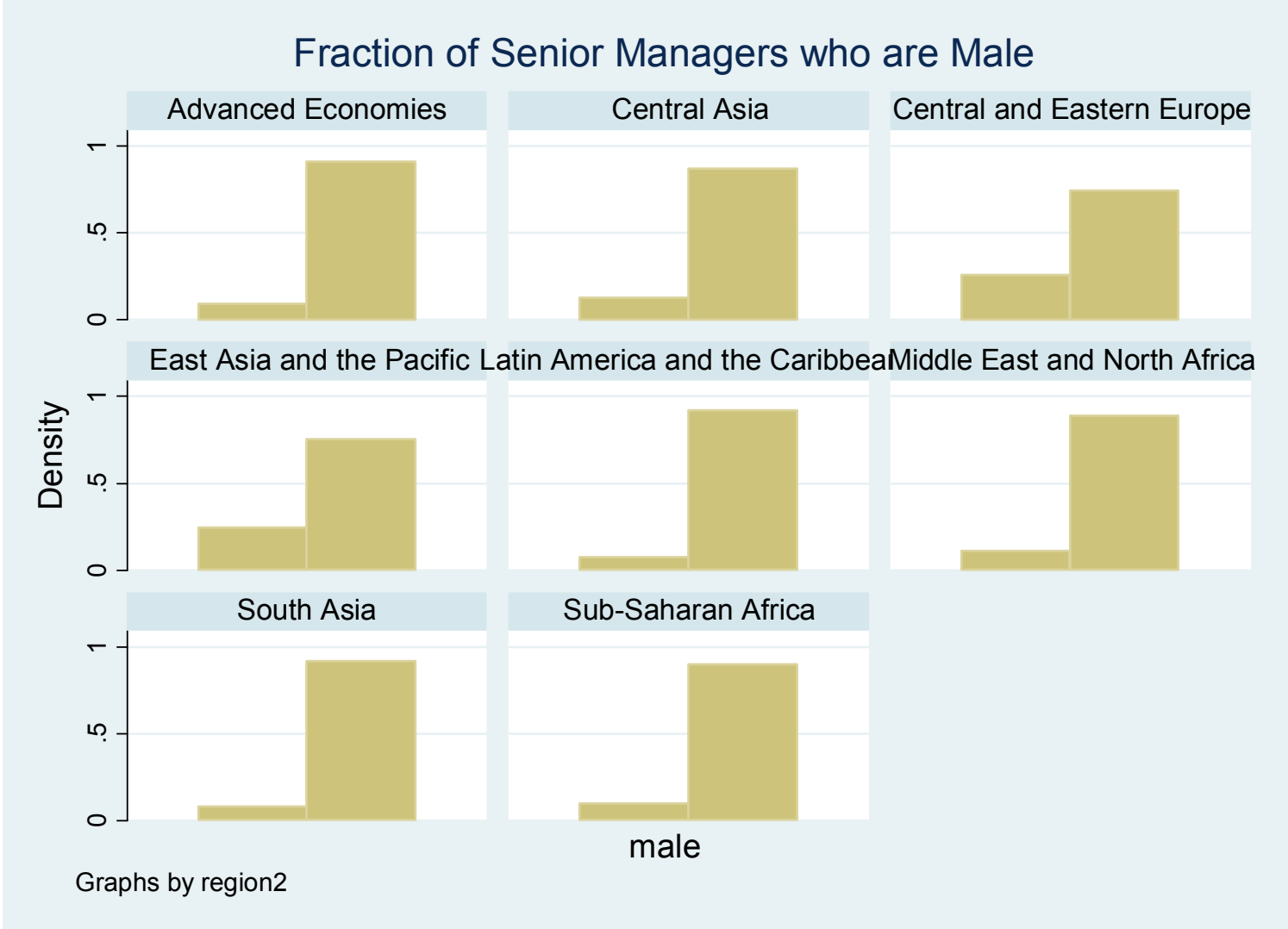

Note: The figure presents the fraction our senior manager by gender among our sample of applicants to International Monetary Fund training activities during the period 1991-2011 for height different regions. For each region, the figure presents the fraction of female (left hand side) and male (right hand side) senior manager. 
Figure 19. Education Attainment by Agency and Region

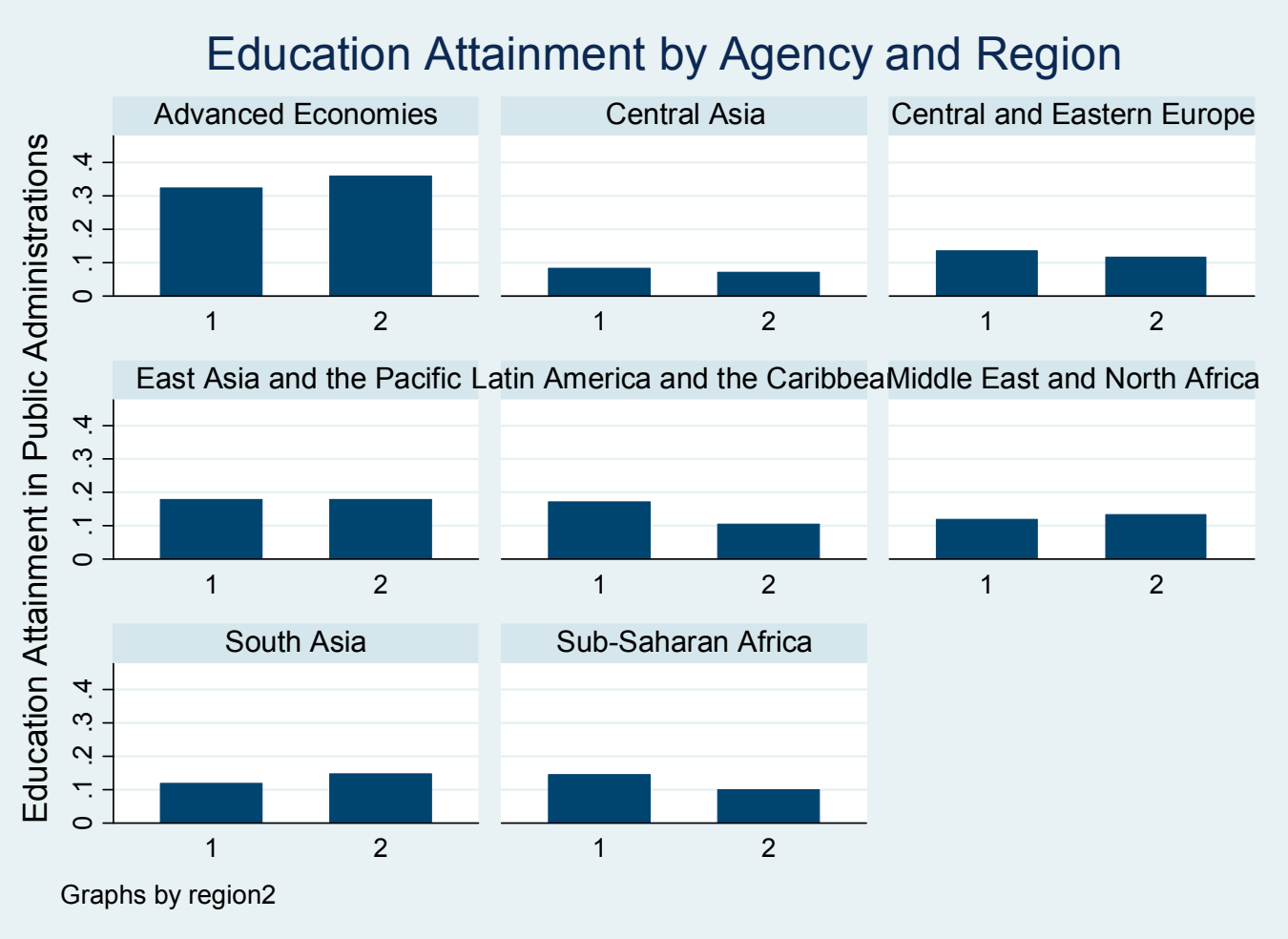

Note: The figure presents our quality adjusted measure of education attainments of applicants to International Monetary Fund training activities during the period 1991-2011 for height different regions. For each region, we present the level of education attainment for two different agencies. 1 stands for the ministry of finance and economics and 2 stands for central banks. 
Figure 20. Education attainment and Relative Public Sector Pay

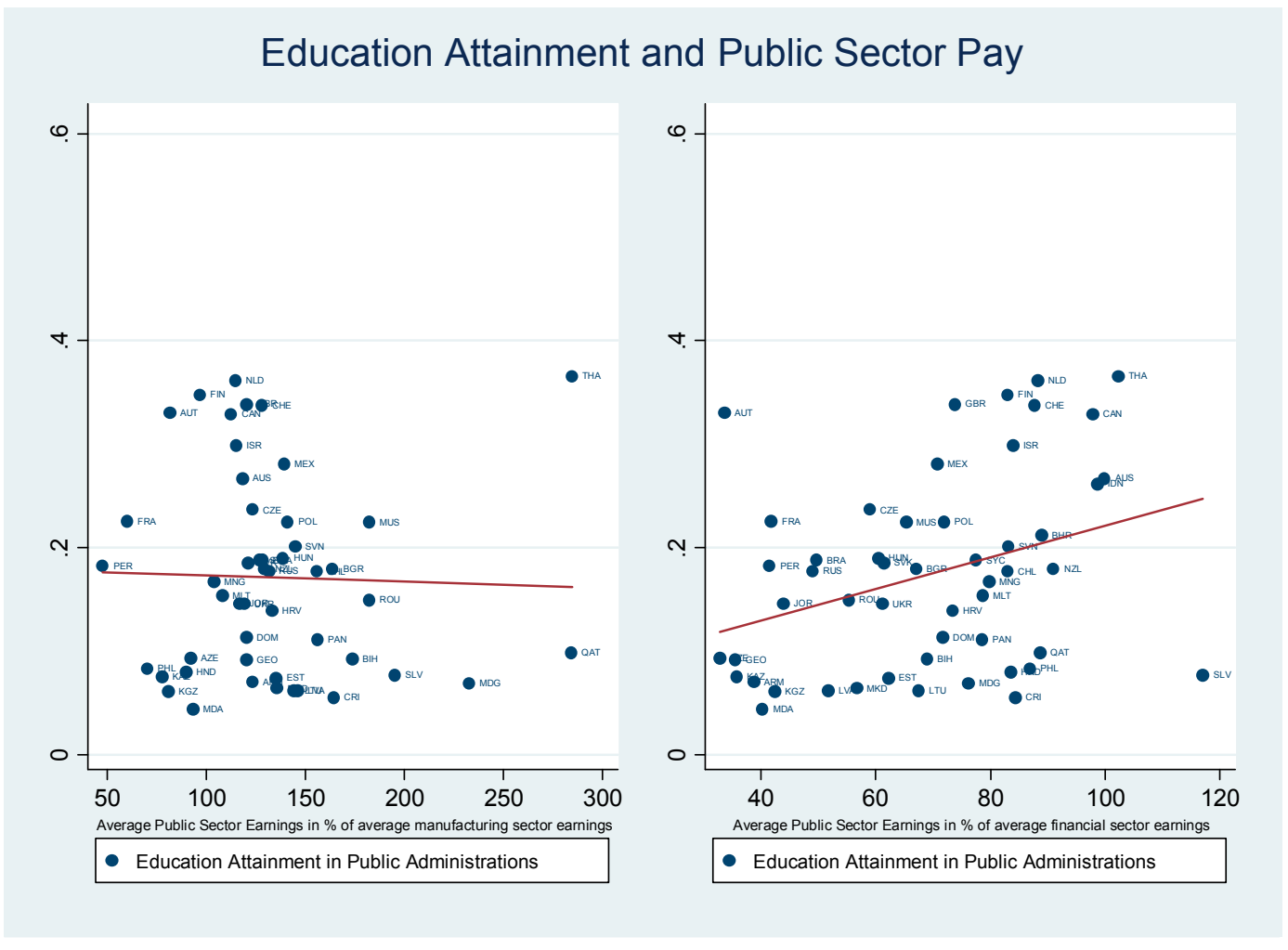

Note: The figure presents the cross-correlations between our measure of adjusted education attainment in public administrations (X-axis in both panels) and ratio of public sector pay over manufacturing (left hand side panel Y-axis)/financial sector (right hand side panel Y-axis) or height different regions. The data on civil servants' pay is from Clements et al. (2010). 
Figure 21. Education attainment and tax collection

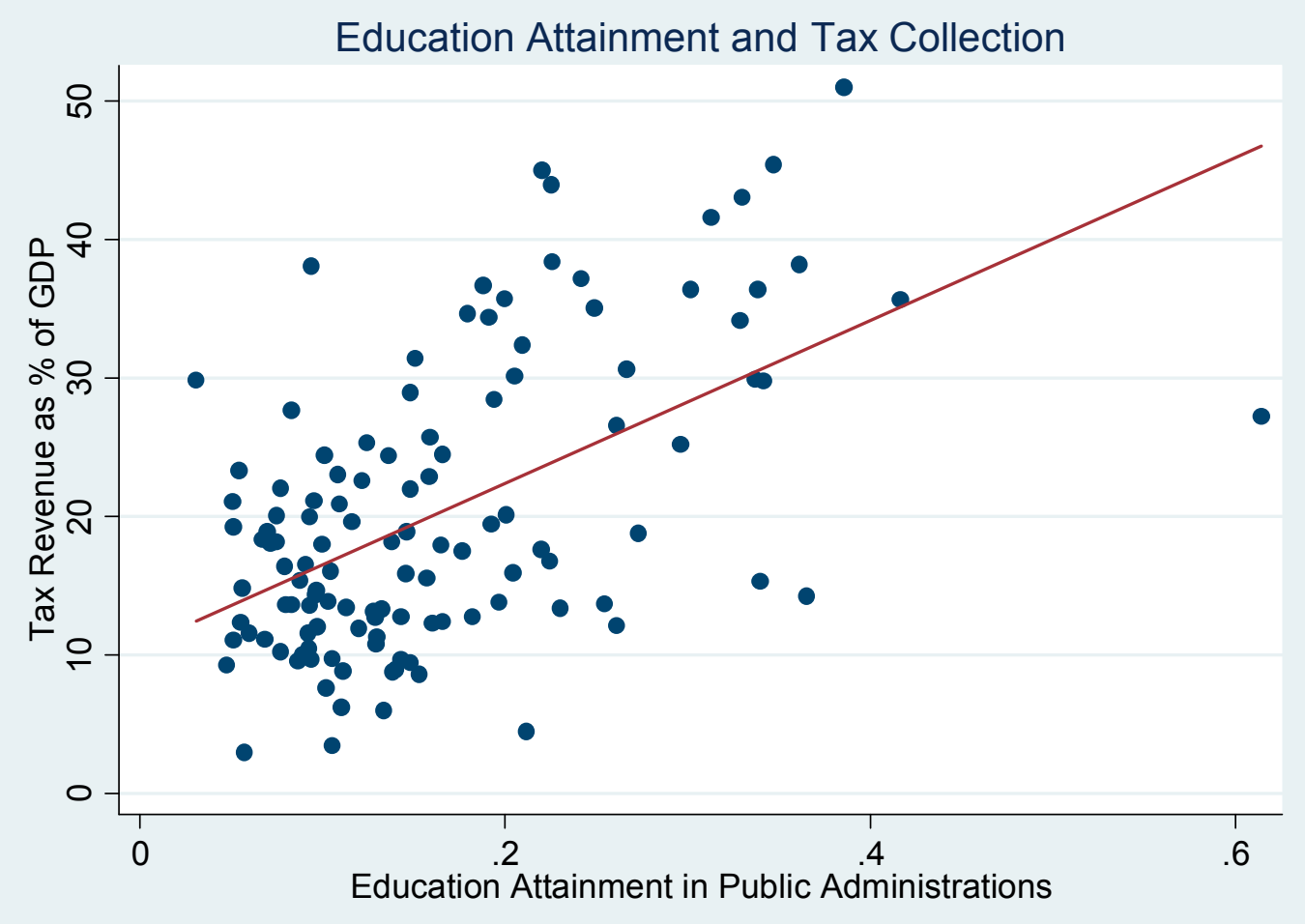

Note: The figure presents the cross-correlations between our measure of adjusted education attainment in public administrations (X-axis in both panels) and tax revenue over GDP. The data on tax revenue is from Baunsgaard and Keen (2010).

Figure 22. Education attainment and tax revenues controlling GDP per education and education

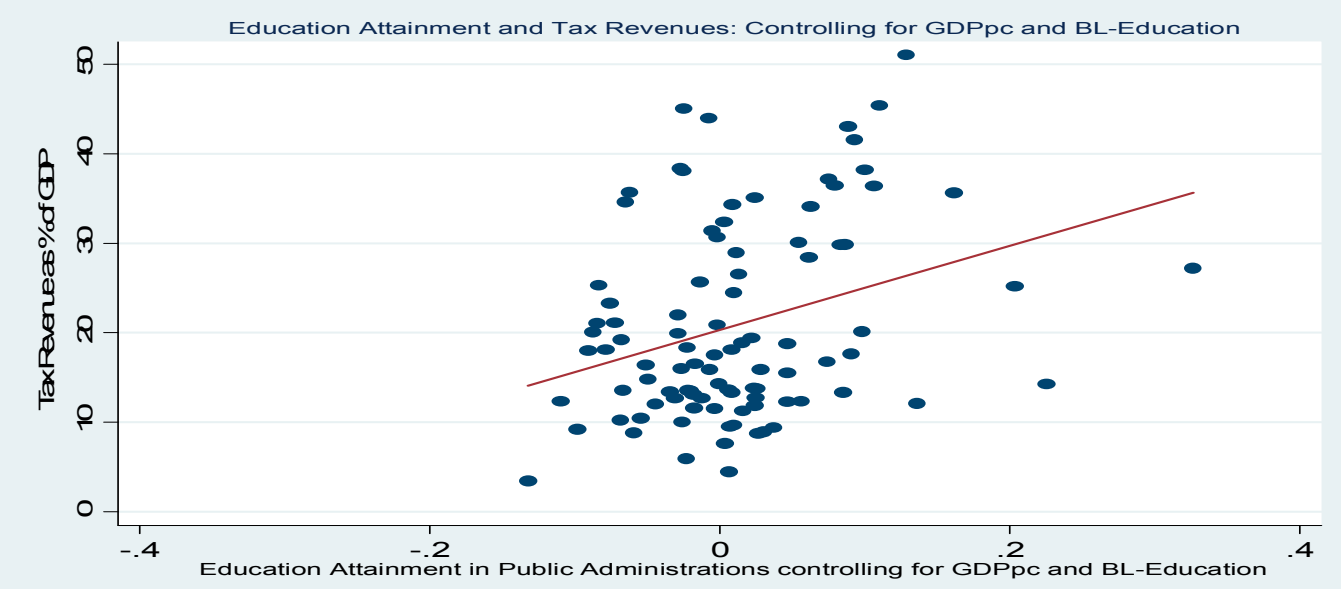

Note: The figure presents the cross-correlations between our measure of adjusted education attainment in public administrations (X-axis) and tax revenue over GDP (Y-axis) controlling for both GDP per capita and education attainment in the general population. The data on tax revenue is from Baunsgaard and Keen (2010). The data on education attainment in the general population are from Barro and Lee (2012) 
Figure 23. Education attainment and corruption

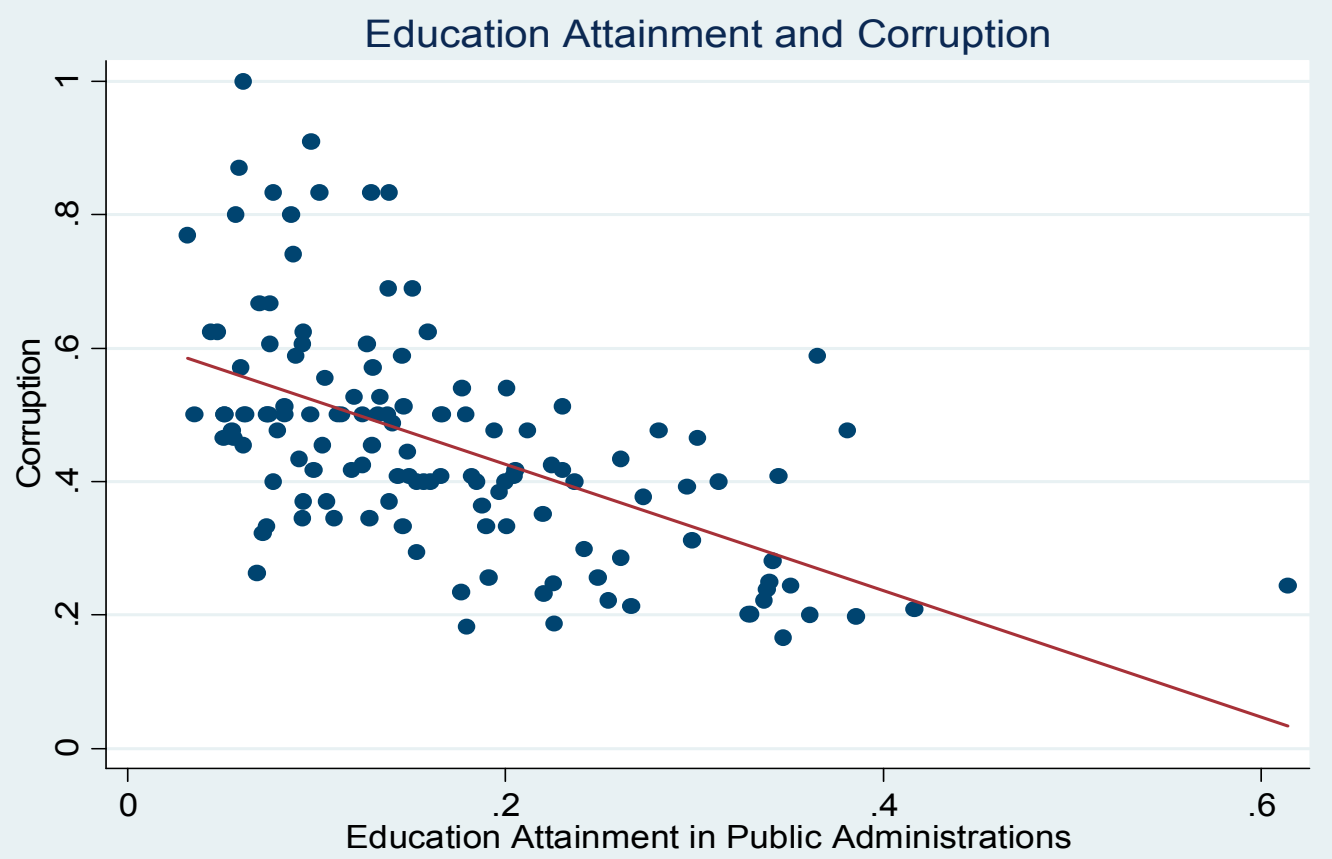

Note: The figure presents the cross-correlations between our measure of adjusted education attainment in public administrations (X-axis in both panels) and an indicator of corruption. The indicator of corruption based on PRS Group 2012 data 
Figure 24. Education Attainment and Corruption controlling for GDP per capita and Barro Lee

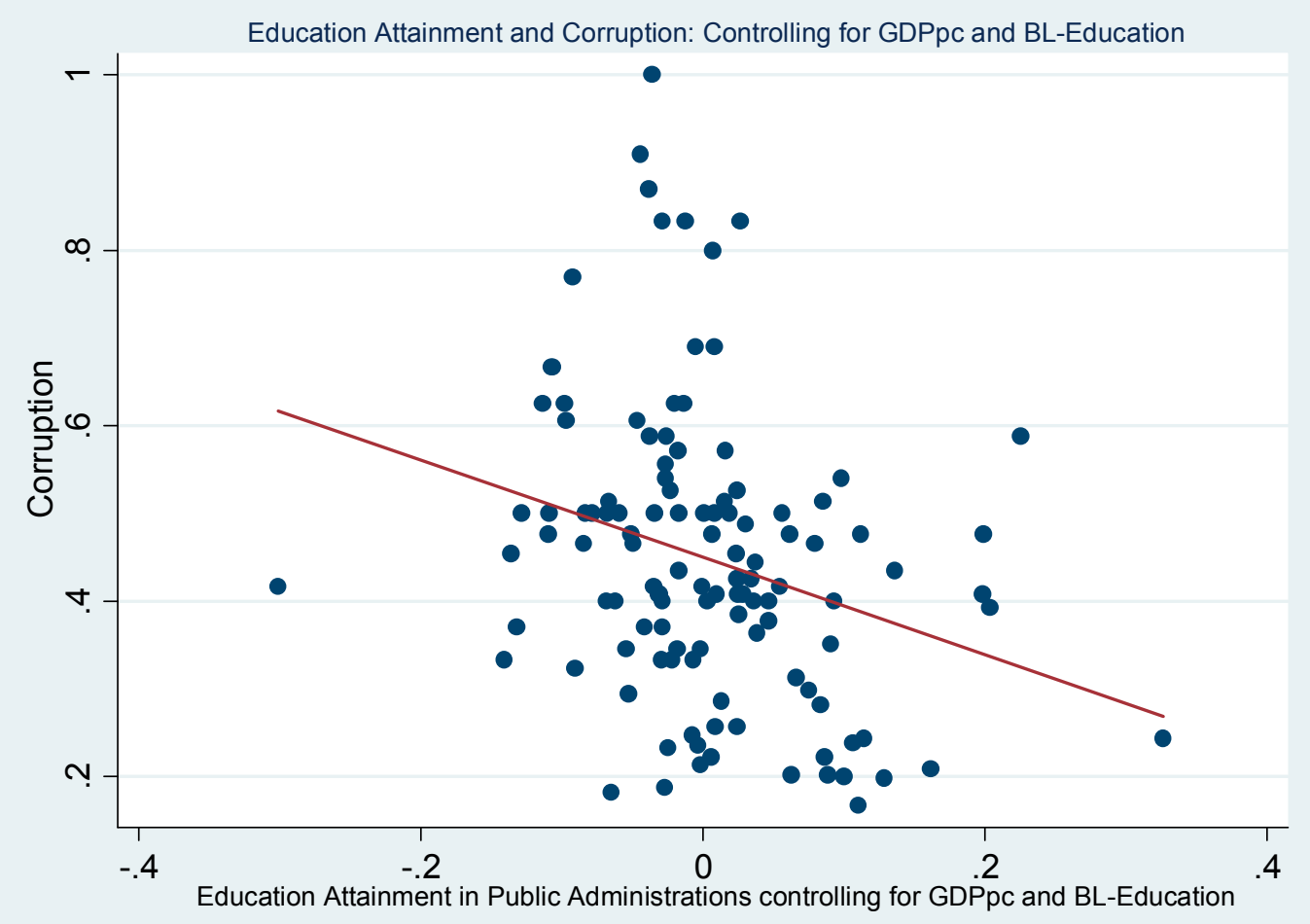

Note: The figure presents the cross-correlations between our measure of adjusted education attainment in public administrations (X-axis) and corruption (Y-axis) controlling for both GDP per capita and education attainment in the general population. The data on GDP per capita is from Heston and Summers (2009). Education attainment data in the general population is from Barro and Lee (2012) 
Figure 25. Education Attainment and Public Sector Management

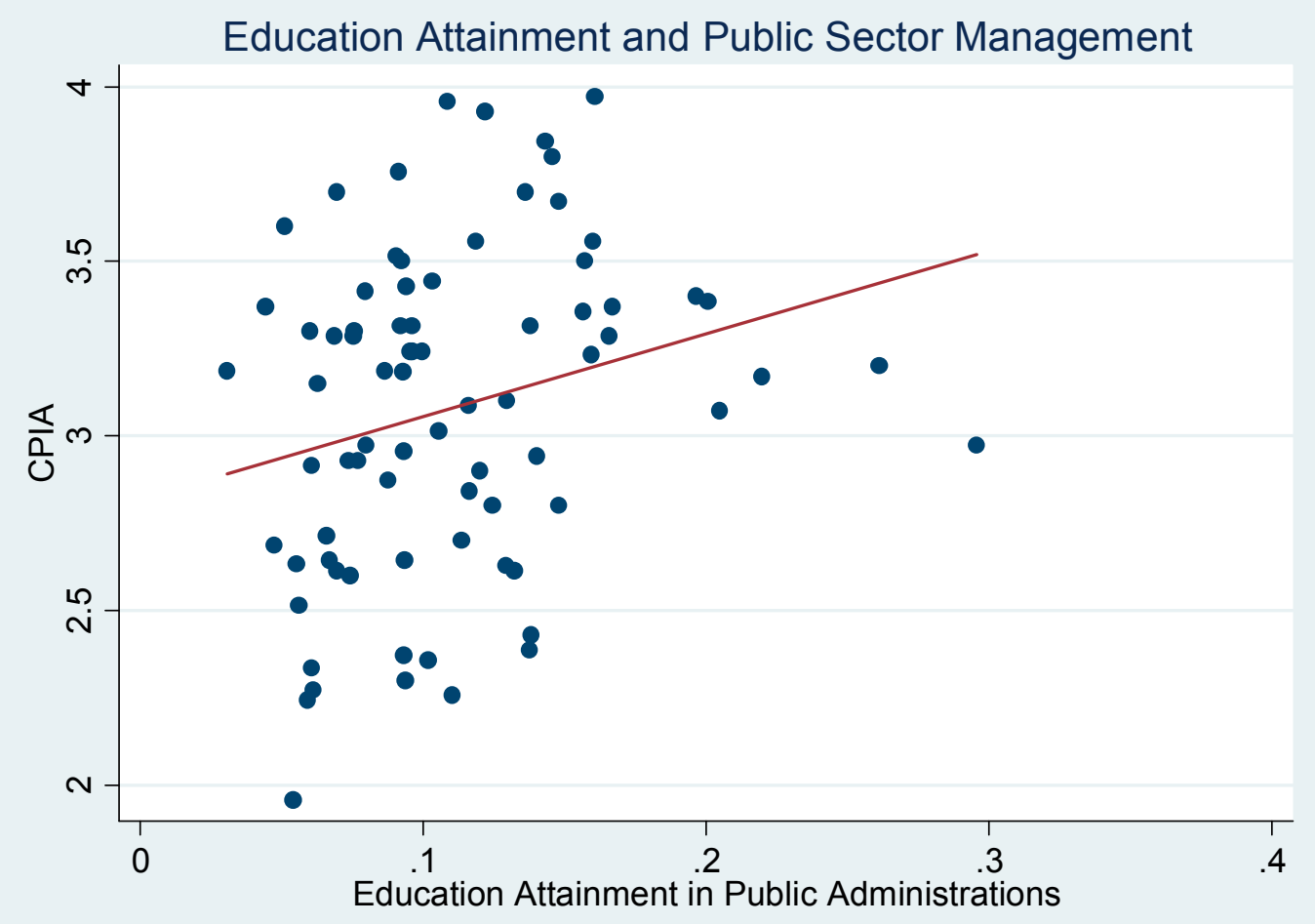

Note: The figure presents the cross-correlations between our measure of adjusted education attainment in public administrations (X-axis) and public sector management (Y-axis). The data on public sector management is from World Bank Development Indicators (2011). 
Figure 26. Education attainment and bureaucratic quality

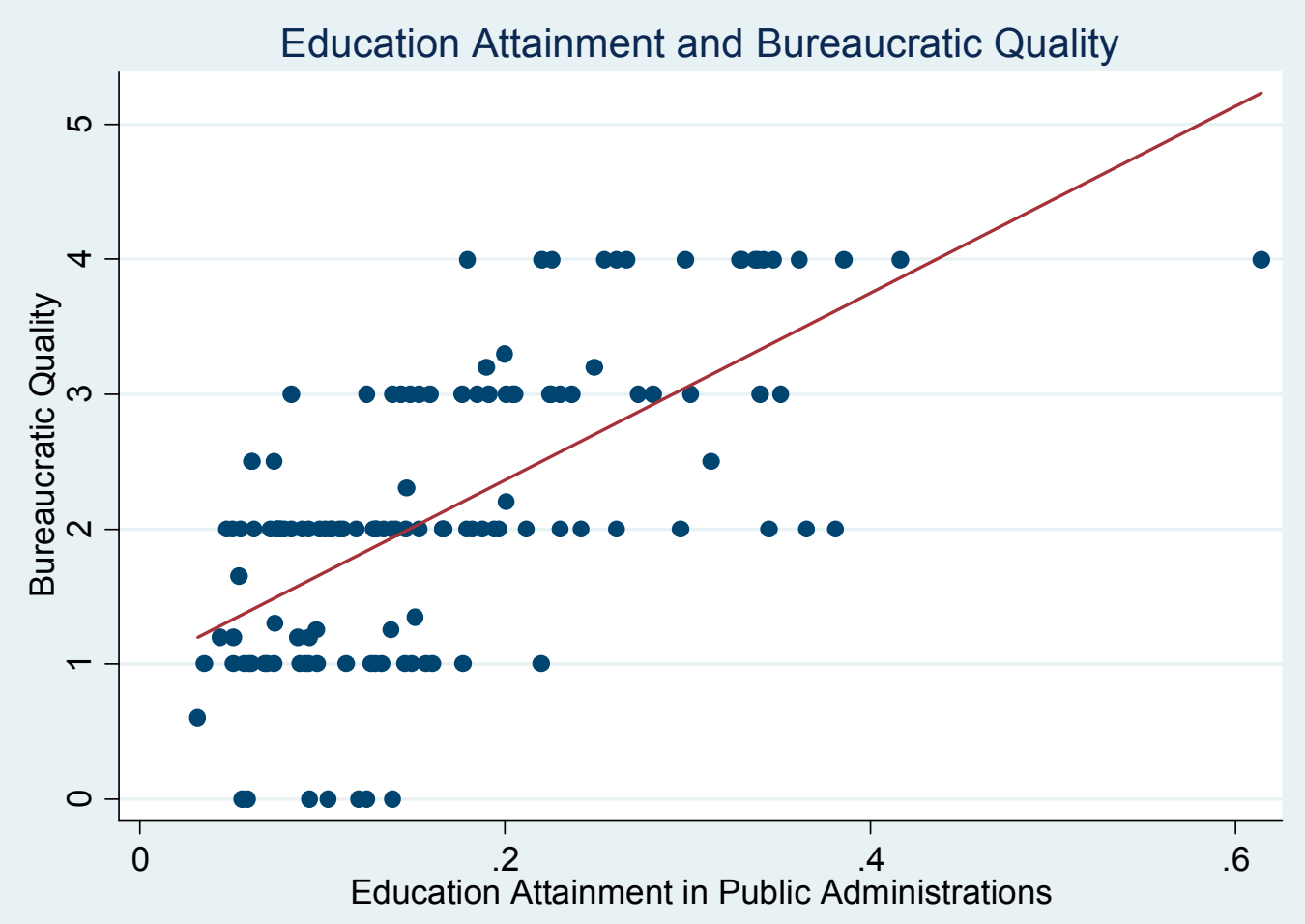

Note: The figure presents the cross-correlations between our measure of adjusted education attainment in public administrations (X-axis) and bureaucratic quality (Y-axis). The data on bureaucratic quality is from PRS Group (2012). 
Figure 27. Education and Domestic Financial Sector Standards

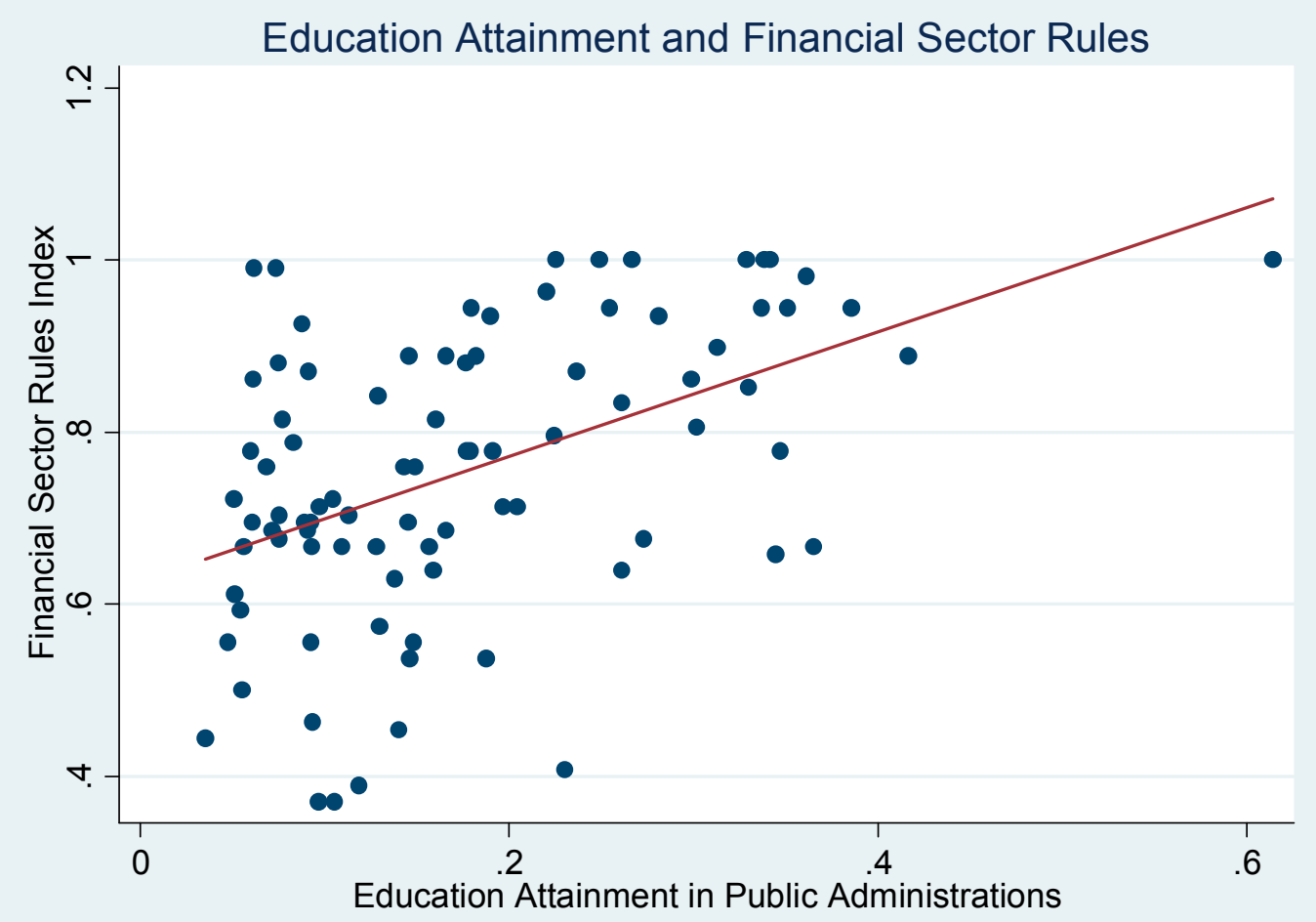

Note: The figure presents the cross-correlations between our measure of adjusted education attainment in public administrations (X-axis) and financial sector liberalization (Y-axis). The data on financial liberalization is from Ostry (2009). 
Table 1. Country Level Academic Ranking

\begin{tabular}{|c|c|c|c|c|c|c|c|c|c|c|c|}
\hline & & & & OUTPI & & & & & & & \\
\hline & SCORE & RANK & 01 & 02 & 03 & 04 & 05 & 06 & 07 & 08 & 09 \\
\hline Argentina & 23.3 & 36 & 14 & 7.0 & 46.4 & 2.0 & 7.6 & 66.1 & 24.9 & 13.7 & 61.2 \\
\hline Australia & 54.0 & 7 & 9.7 & 88.9 & 78.8 & 58.5 & 34.3 & 73.1 & 67.2 & 55.2 & 49.2 \\
\hline Austria & 42.1 & 18 & 2.5 & 60.6 & 79.0 & 46.8 & 19.8 & 58.0 & 31.6 & 54.0 & 64.6 \\
\hline Belgium & 46.6 & 14 & 3.5 & 65.2 & 84.1 & 49.8 & 28.3 & 64.9 & 51.9 & 45.0 & 66.4 \\
\hline Brazil & 24.9 & 34 & 8.8 & 9.3 & 40.5 & 2.0 & 19.9 & 34.7 & 18.3 & 9.2 & 81.6 \\
\hline Bulgaria & 23.2 & 37 & 0.2 & 5.7 & 38.6 & 0.0 & 0.0 & 51.0 & 37.5 & 20.7 & 78.8 \\
\hline Canada & 60.0 & 3 & 14.6 & 87.8 & 82.3 & 50.3 & 43.4 & 85.8 & 80.1 & 56.9 & 59.0 \\
\hline Chile & 22.1 & 39 & 10 & 12.1 & 49.9 & 4.9 & 8.1 & 57.0 & 38.0 & 11.0 & 37.7 \\
\hline China & 33.5 & 26 & 43.5 & 6.6 & 34.1 & 0.9 & 19.8 & 23.4 & 16.3 & 15.7 & n.a. \\
\hline Croatia & 21.7 & 40 & 0.5 & 23.7 & 39.6 & 9.6 & 4.0 & 47.3 & 25.4 & 20.5 & na. \\
\hline Czech Republic & 31.1 & 30 & 1.7 & 33.0 & 46.7 & 6.1 & 6.1 & 58.4 & 24.3 & 36.0 & 96.1 \\
\hline Denmark & 55.0 & 6 & 2.4 & 89.7 & 89.1 & 71.4 & 31.8 & 71.6 & 57.5 & 83.9 & 49.4 \\
\hline Finland & 57.4 & 4 & 2.5 & 93.3 & 76.9 & 56.9 & 21.2 & 88.2 & 56.9 & 100.0 & 74.6 \\
\hline France & 41.2 & 19 & 10.2 & 33.1 & 77.4 & 24.6 & 39.9 & 52.5 & 44.0 & 48.2 & 54.8 \\
\hline Germany & 52.5 & 9 & 20.3 & 51.0 & 79.2 & 33.4 & 37.7 & 67.0 & 43.8 & 49.9 & 85.9 \\
\hline Greece & 33.4 & 27 & 2.5 & 45.7 & 60.6 & 10.2 & 11.0 & 86.0 & 35.1 & 24.5 & 53.8 \\
\hline Hong Kong SAR & 39.8 & 21 & 2.7 & 79.0 & 77.6 & 45.1 & 19.8 & 57.8 & 28.7 & 43.2 & 38.9 \\
\hline Hungary & 29.8 & 31 & 10 & 21.3 & 51.4 & 10.1 & 9.7 & 59.4 & 26.8 & 26.2 & 90.8 \\
\hline India & 16.2 & 45 & 5.7 & 10 & 46.2 & 0.0 & 4.9 & 15.6 & n.a. & 1.8 & n.a. \\
\hline Indonesia & 110 & 48 & 0.1 & 0.1 & 43.3 & 0.0 & 0.0 & 21.5 & 7.9 & 1.2 & 36.8 \\
\hline Iran & 19.6 & 42 & 2.8 & 7.8 & 45.4 & 0.7 & 4.9 & 41.2 & 28.7 & 9.8 & 47.3 \\
\hline Ireland & 42.2 & 17 & 1.4 & 65.0 & 77.4 & 36.9 & 15.8 & 60.2 & 48.3 & 43.7 & 71.8 \\
\hline Israel & 47.1 & 13 & 2.9 & 79.3 & 71.3 & 74.5 & 30.3 & 60.2 & 77.5 & n.a. & 57.7 \\
\hline Italy & 36.7 & 25 & 13.9 & 47.0 & 72.0 & 20.5 & 25.5 & 63.5 & 21.7 & 22.2 & 42.4 \\
\hline Japan & 49.4 & 11 & 25.1 & 40.3 & 54.5 & 13.3 & 45.7 & 56.8 & 54.7 & 67.4 & 64.8 \\
\hline Korea & 42.5 & 16 & 9.4 & 39.3 & 54.8 & 12.1 & 21.1 & 100.0 & 57.7 & 63.6 & n.a. \\
\hline Malaysia & 15.4 & 47 & 12 & 8.4 & 39.5 & 1.5 & 4.0 & 36.1 & 9.3 & 4.7 & 46.7 \\
\hline Mexico & 15.6 & 46 & 2.1 & 4.0 & 39.5 & 0.7 & 7.6 & 26.0 & 28.0 & 4.7 & 37.6 \\
\hline Netherlands & 51.1 & 10 & 7.2 & 88.7 & 96.7 & 65.0 & 33.9 & 60.4 & 51.1 & 37.0 & 53.3 \\
\hline New Zealand & 45.0 & 15 & 1.5 & 70.3 & 75.1 & 58.1 & 16.2 & 79.6 & 46.2 & 56.6 & 45.2 \\
\hline Norway & 47.9 & 12 & 1.7 & 70.5 & 80.6 & 58.8 & 23.6 & 710 & 53.0 & 72.0 & 46.4 \\
\hline Poland & 29.0 & 32 & 4.0 & 21.6 & 41.1 & 2.7 & 9.7 & 67.9 & 34.4 & 21.0 & 77.9 \\
\hline Portugal & 33.0 & 28 & 2.3 & 44.7 & 65.7 & 8.7 & 8.9 & 59.9 & 210 & 56.6 & 57.2 \\
\hline Romania & 22.3 & 38 & 0.9 & 8.4 & 40.1 & 0.0 & 0.0 & 61.4 & 20.9 & 11.8 & 78.9 \\
\hline Russian Federation & 31.4 & 29 & 2.2 & 3.1 & 27.1 & 1.2 & 15.9 & 73.1 & 100.0 & 40.5 & n.a. \\
\hline Singapore & 39.6 & 22 & 0.3 & 77.9 & 78.8 & 30.4 & 9.0 & n.a. & 39.8 & 73.1 & 40.0 \\
\hline Slovakia & 26.3 & 33 & 0.4 & 14.2 & 40.6 & 0.0 & 0.0 & 52.1 & 24.1 & 32.1 & 100.0 \\
\hline Slovenia & 37.0 & 24 & 0.5 & 55.4 & 49.7 & 20.9 & 4.0 & 83.7 & 37.9 & 48.4 & 70.0 \\
\hline South Africa & 19.0 & 43 & 1.7 & 6.9 & 58.6 & 3.1 & 15.0 & n.a. & 1.3 & 5.2 & n.a. \\
\hline Spain & 39.1 & 23 & 9.3 & 41.2 & 64.4 & 12.3 & 18.3 & 70.5 & 45.5 & 38.2 & 66.8 \\
\hline Sweden & 56.7 & 5 & 4.6 & 100.0 & 82.8 & 93.3 & 36.2 & 68.1 & 50.2 & 65.8 & 56.2 \\
\hline Switzerland & 54.0 & 8 & 3.5 & 927 & 100.0 & 100.0 & 41.6 & 49.5 & 56.7 & 43.1 & 45.8 \\
\hline Taiwan & 39.9 & 20 & 6.5 & 57.6 & 56.7 & 16.6 & 9.0 & 62.6 & 67.7 & 59.3 & n.a. \\
\hline Thailand & 17.9 & 44 & 12 & 3.7 & 53.1 & 0.0 & 0.0 & 44.4 & 23.4 & 4.4 & n.a. \\
\hline Turkey & 21.1 & 41 & 5.3 & 15.3 & 43.5 & 0.7 & 4.9 & 44.1 & 18.5 & 10.7 & 53.3 \\
\hline Ukraine & 23.7 & 35 & 0.3 & 1.4 & 25.3 & 0.0 & 0.0 & 76.5 & 69.4 & 17.6 & n.a. \\
\hline United Kingdom & 62.2 & 2 & 24.8 & 81.4 & 90.8 & 55.4 & 70.0 & 56.3 & 57.5 & 51.6 & 64.5 \\
\hline United States & 100.0 & 1 & 100.0 & 66.0 & 95.5 & 50.2 & 100.0 & 85.8 & 70.5 & 61.3 & 77.9 \\
\hline
\end{tabular}

Note: The figure presents the Universitas (2012) ranking of countries in terms of the performance of the higher education system. The variables Q1-Q9 are sub-indices of the overall score. The data and further details on the sub-indices and indices are available on website listed below: http://www.universitas21.com/article/collaborations/details/105/measure-4-output 